\title{
Comparative voltammetric and FTIRRAS study on the electro-oxidation of thiourea and methyl-thioureas on platinum in aqueous acid solutions
}

\author{
A.E. Bolzán ${ }^{\text {a,* }}$, P.L. Schilardi a , R.C.V. Piatti ${ }^{\text {a }}$, T. Iwasita ${ }^{\text {b }}$, A. Cuesta ${ }^{\text {c }}$, \\ C. Gutiérrez ${ }^{c}$, A.J. Arvia ${ }^{\text {a }}$ \\ ${ }^{a}$ Instituto de Investigaciones Fisicoquímicas Teóricas y Aplicadas (INIFTA) (UNLP, CONICET), Sucursal 4, Casilla de Correo 16, \\ (1900) La Plata, Argentina \\ ${ }^{\mathrm{b}}$ Instituto de Quimica de São Carlos, Universidade de São Paulo, São Carlos, Brazil \\ "Instituto de Química Física "Rocasolano", C.S.I.C., C. Serrano, 119, E-28006 Madrid, Spain
}

Received 16 December 2003; received in revised form 15 April 2004; accepted 22 April 2004

Available online 2 July 2004

\begin{abstract}
A comparative voltammetric and spectroscopic study on thiourea, methylthiourea, 1,3 dimethylthiourea and tetramethylthiourea electro-oxidation is presented. The investigation was performed at platinum electrodes in aqueous acid solutions in the potential range between 0.05 and $1.6 \mathrm{~V}$ (versus SHE). The electro-oxidation of thioureas starts at ca. $0.55 \mathrm{~V}$ and it involves at least two reaction stages irrespective of their nature. The first electro-oxidation stage occurs in the range $0.55-0.9 \mathrm{~V}$ and involves the formation of a soluble disulphide derivative influenced by the blockage of the electrode surface. The second electro-oxidation stage occurs in the range 0.9-1.6 V and it involves a complex electrochemical process yielding products such as carbon dioxide, sulphate ions, $\mathrm{CN}$ - and CO-containing species. The second electro-oxidation stage is likely mediated by the oxygen-containing layer that is produced electrochemically on platinum in that range of potential. The gradual depletion of thioureas and the progressive formation of soluble products in the thin solution layer in contact with the electrode are followed through changes in the band intensities of IR spectra. From the correlation between voltammetric and spectroscopic data a description of global reactions involving the electrooxidation of thioureas to soluble products in both potential ranges is presented. The proposed reaction pathways are consistent with the participation of different adsorbates as was reported earlier for thioureas on platinum.
\end{abstract}

(c) 2004 Elsevier B.V. All rights reserved.

Keywords: Thiourea; Methylthiourea; Dimethylthiourea; Tetramethylthiourea; Electro-oxidation; Platinum; FTIRRAS

\section{Introduction}

In recent years, the study of the electrochemical behaviour of thioureas (TUs) at different metals has been of increasing interest due to their application as additives for metal electrodeposition and corrosion inhibition [1-3]. In earlier work the nature and concentration of each TU related to its optimal efficiency was selected empirically. For instance, it is well established that the specific optimal efficiency of TU in either metal plating

\footnotetext{
${ }^{*}$ Corresponding author. Tel.: +54-2214257430; fax: $\quad+54-$ 2214254642.

E-mail address: aebolzan@inifta.unlp.edu.ar (A.E. Bolzán).
}

or corrosion protection depends considerably on the bath composition, the critical additive concentration and its stability in solution under either open circuit or an applied electric potential [4-6].

In general, additives modify the kinetics and mechanism of the electrochemical process. For TU, these changes depend on the strength of metal-thiol interactions that are favoured by the tautomeric form of $\mathrm{TU}$ $\left(\mathrm{H}_{2} \mathrm{NHNCSH}\right)$, which, in turn, depends on the solution composition and the strength of the electric field at the metal|solution interface $[7,8]$.

For $E<0.5 \mathrm{~V}$ (versus SHE), TU adsorption involves the protonation-deprotonation equilibrium $\mathrm{TU}(\mathrm{aq}) \rightleftharpoons$ $\mathrm{TU}^{*}(\mathrm{ad})+\mathrm{H}^{+}+\mathrm{e}^{-}$, where (aq) and (ad) stand for 
aqueous-solvated and adsorbed species, respectively [9]. Conversely, for $E>0.5 \mathrm{~V}$, TU-containing surface complex species can be formed electrochemically $[10,11]$. These adsorbed species can be considered as precursors of the metal electrodissolution processes as soluble TUligand metal complexes. This type of product has been found for a number of metals in acidic solutions [12-21] even in the absence of amine hydrogens in the TU molecules, as in tetramethylthiourea (TMTU). In this case, the electron transfer reaction alone could produce both adsorbates and dimerisation as occurs on gold [11].

Recently, voltammetric data of the formation of TU and methyl-substituted TU adsorbates on platinum showed that the corresponding adsorption kinetics follow an Elovich-type rate equation and, under equilibrium conditions, adsorption data fit a Frumkin-type isotherm including repulsive adsorbate-adsorbate interactions. For different TUs, the corresponding degree of surface coverage by adsorbates decreases according to the corresponding cross section of each molecule [16].

In this work we attempt to establish a correlation between the voltammetric behaviour of TU, methylthiourea (MTU), 1,3 dimethylthiourea (DMTU) and tetramethylthiourea (TMTU) on polycrystalline platinum in aqueous acid solutions, and the formation of soluble electro-oxidation products at different potentials. Fourier transform infrared reflection absorption spectra (FTIRRAS) are used for monitoring the formation of a number of soluble electro-oxidation products and the disappearance of reactants. This procedure makes it possible to determine unambiguously the variation of the nature of products and their concentration change at the thin layer of solution in contact with the working electrode surface in different ranges of potentials. From these correlations two limiting reaction pathways that are applicable at low and high applied potentials, irrespective of the TU solution can be proposed. These reaction pathways involve the participation of both homogeneous reactions in solution and surface electrochemical reactions including adsorption processes [16].

\section{Experimental}

\subsection{Electrochemical measurements}

A conventional three-electrode electrochemical glass cell was utilised. The working electrode consisted of a polycrystalline platinum wire (J. Matthey, spec pure, real area, $0.4 \mathrm{~cm}^{2}$ ) and a mercurous sulphate electrode (MSE) was used as the reference electrode. The working electrode surface was first polished with an alumina $(0.3 \mu \mathrm{m}$ grit) water suspension and subsequently washed repeatedly with Milli-Q* water. The area of the working electrode was determined from the hydrogen adatom voltammetric charge [22]. Runs were also made using a rotating platinum ring-disc electrode (type EAD 10K Tacussel) of $0.12 \mathrm{~cm}^{2}$ geometric area and collection efficiency $N=0.24$. The potential applied to the disc $\left(E_{\mathrm{D}}\right)$ was in the range $0.05 \leqslant E_{\mathrm{D}} \leqslant 1.55 \mathrm{~V}$, whereas the potential at the ring $\left(E_{\mathrm{R}}\right)$ was kept constant at $0.15 \mathrm{~V}$ and the rotation speed varied in the range $0 \leqslant \omega \leqslant 2000 \mathrm{rpm}$.

Voltammetric runs were performed using plain aqueous $0.5 \mathrm{M}$ sulphuric acid or aqueous $1 \mathrm{mM} \mathrm{X}+0.5 \mathrm{M}$ sulphuric acid ( $\mathrm{X}=\mathrm{TU}$, MTU, DMTU, TMTU). Solutions were prepared from Milli-Q* water, sulphuric acid (98\% Merck, p.a.), TU, MTU, DMTU or TMTU (all Fluka, puriss. p.a.). For each experiment only freshly prepared solutions continuously kept under nitrogen $(99.99 \%)$ saturation were used.

The electrochemical set-up comprised a conventional potentiostat and wave generator coupled to a Houston Omnigraphic recorder. Ring-disc measurements were performed using a type BI-PAD Tacussel bipotentiostat.

\subsection{FTIRRAS measurements}

The electrochemical cell for in situ FTIRRAS measurements consisted of a conventional three-electrode design [23] with a fluorite $60^{\circ}$ prism at the bottom of the cell. A polycrystalline platinum disc $(1.2 \mathrm{~cm}$ dia.) was used as the working electrode. Before each run, this electrode was polished to mirror grade with $0.3 \mu \mathrm{m}$ grid alumina and rinsed with Milli-Q* ${ }^{*}$ water. A platinum sheet and a reversible hydrogen electrode in the working solution (RHE) were used as counter and reference electrodes, respectively.

For FTIRRAS measurements the concentration of TUs was increased from $1 \mathrm{mM}$ to $0.1 \mathrm{M}$ in order to obtain significant changes in the thin solution layer spectra. The spectra were measured in aqueous solutions of either $0.1 \mathrm{M} \mathrm{X}+0.1 \mathrm{M}$ perchloric acid or $0.1 \mathrm{M}$ sulphuric acid ( $\mathrm{X}=\mathrm{TU}$, MTU, DMTU, TMTU). Solutions were prepared from perchloric acid $(70 \%$ Alfa Aesar, p.a.), sulphuric acid (98\% Merck, p.a.) and Milli$\mathrm{Q}^{*}$ water. The use of perchloric instead of sulphuric acid avoided the interference of the latter in the evaluation of the IR bands corresponding to sulphate ions produced from the electro-oxidation of TUs. As no other difference was observed between the two systems, only those spectra obtained with aqueous perchloric acid solutions are reported here for simplicity.

As sulphuric acid involves an intrinsic lower content of water, compared to perchloric acid, $0.1 \mathrm{M}$ sulphuric acid (Mallinckrodt AR, 99.9\%) in deuterium oxide was used to study the FTIRRAS spectra in the region where water bands overlap those of TUs and disulphides formed from electro-oxidation of TUs, such as formamidine disulphide (FDS) from TU.

Spectra were recorded using freshly prepared nitrogen-saturated solutions to minimise any influence of 
byproducts resulting from a possible spontaneous decomposition of TUs.

Measurements were performed using a Nicolet Nexus 670 FTIR spectrometer coupled to a Wenking 72L potentiostat. Each set of spectra was obtained by increasing the potential $0.05 \mathrm{~V}$ stepwise from 0.05 to $1.6 \mathrm{~V}$. At each potential 256 interferometer scans with $8 \mathrm{~cm}^{-1}$ resolution were collected. Normalised reflectance spectra were calculated as $R / R_{0}$, where $R$ is the value of the reflectance at the sampling potential $E_{\mathrm{s}}$ and $R_{0}$ is the reflectance measured at a reference potential $E_{\text {ref }}$ $\left(E_{\text {ref }}=0.05 \mathrm{~V}\right)$.

Spectra with either $p$ - or $s$-polarised light were recorded to collect information either from both soluble and adsorbed species or exclusively from soluble species in the thin solution layer. In the spectra, positive- and negative-going absorption bands represent the loss and gain of species at $E_{\mathrm{s}}$ as compared to $E_{\text {ref }}$, respectively. All runs were performed at $298 \mathrm{~K}$ and potentials in the text are referred to the SHE scale.

\section{Results}

\subsection{Voltammetry in the range $0.05-1.5 \mathrm{~V}$}

Blank voltammograms run at $0.05 \mathrm{~V} \mathrm{~s}^{-1}$ between 0.05 and $1.5 \mathrm{~V}$ confirm the well-known voltammetric features of polycrystalline platinum [22] in aqueous $0.5 \mathrm{M}$ sulphuric acid (Fig. 1, dotted lines). Briefly, they exhibit the hydrogen atom electrosorption reaction $(0.05 \leqslant E \leqslant$ $0.45 \mathrm{~V}$ ), the oxygen-containing monolayer formation and electroreduction $(0.6 \leqslant E \leqslant 1.5 \mathrm{~V})$, and the double layer region $(0.45 \leqslant E \leqslant 0.5 \mathrm{~V})$.

Cyclic voltammograms from all TU-containing solutions show a strong inhibition of hydrogen electrosorption reactions (Fig. 1(a)-(d)). The positive potential scan shows that the electro-oxidation threshold potential for TUs is close to $0.55 \mathrm{~V}$. This process involves two main electro-oxidation regions, the first one in the range 0.6-0.9 V (current hump Ia), and the second one in the range $0.9-1.5 \mathrm{~V}$ (peak IIa).

The reverse potential scan shows first the electroreduction of the oxygen-containing layer on platinum (small cathodic peak at ca. $0.7 \mathrm{~V}$ ) followed by a quasilimiting cathodic current from 0.6 to $0.3 \mathrm{~V}$. From 0.3 to $0.05 \mathrm{~V}$, the increase in the cathodic current is due to the simultaneous electrosorption of TUs and hydrogen atoms on platinum.

In all cases, the stabilised cyclic voltammogram between 0.05 and $1.6 \mathrm{~V}$ exhibits a slight increase in the threshold potential of the first electro-oxidation stage and a decrease in that of the second one. These voltammetric changes may result from the formation of strongly bound residues on the electrode surface [16]. The negative potential shift of peak Ia increases in the
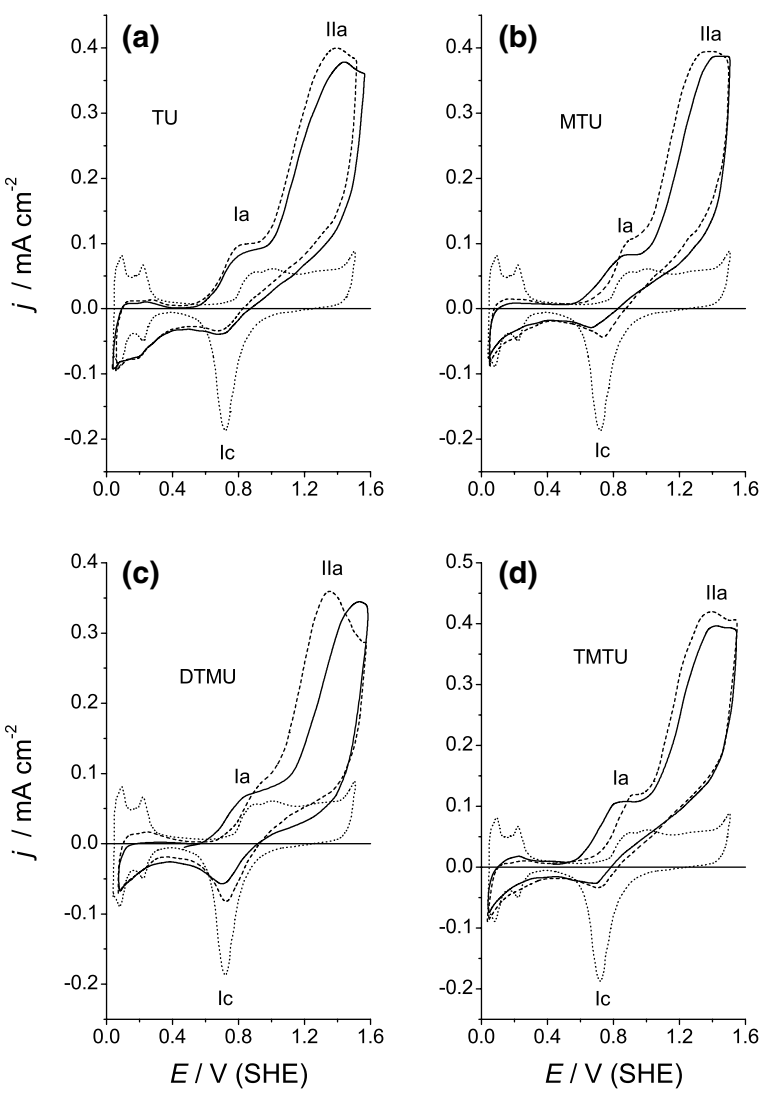

Fig. 1. First (full line) and stabilised (dashed line) voltammograms of platinum run starting from the rest potential upwards in $1 \mathrm{mM}$ TUs $+0.5 \mathrm{M}$ sulphuric acid. Blank (dotted line) in $0.5 \mathrm{M}$ sulphuric acid, $v=0.05 \mathrm{~V} \mathrm{~s}^{-1}, 298 \mathrm{~K}$.

order $\mathrm{TMTU}>\mathrm{DMTU}>\mathrm{MTU}>\mathrm{TU}$ and the positive potential shift of peak IIa becomes more marked for DMTU.

\subsection{Voltammetry in the range $0.05-0.9 \mathrm{~V}$}

Voltammetric runs were also made restricting the potential window to $0.05-0.9 \mathrm{~V}$ measuring from the first to the stabilised cycle, i.e. a cycle that does not differ from the previous one by more than $1 \%$. In all cases, the charges of these voltammograms were evaluated from 0.45 to $0.9 \mathrm{~V}$ (anodic) and from 0.45 to $0.05 \mathrm{~V}$ (cathodic).

For TU-containing solutions, the voltammetric scan restricted to the potential range of the first electro-oxidation stage shows conjugated peaks Ia/Ic in the range 0.35-0.7 V (Fig. 2(a)), which have been related to the redox electrochemical reaction $\mathrm{TU} \rightleftharpoons \mathrm{FDS}+2 \mathrm{H}^{+}+$ $2 \mathrm{e}^{-}[9,24]$. The corresponding anodic and cathodic voltammetric charges for $v=0.05 \mathrm{~V} \mathrm{~s}^{-1}$ are $q_{\mathrm{a}} \simeq$ $750 \mu \mathrm{C} \mathrm{cm}^{-2}$ and $q_{\mathrm{c}} \simeq 165 \mu \mathrm{C} \mathrm{cm}^{-2}$. The peak potential difference $\left(E_{\mathrm{Ia}}^{\mathrm{p}}-E_{\mathrm{Ic}}^{\mathrm{p}} \simeq 0.35 \mathrm{~V}\right)$ indicates the degree of irreversibility of the electrochemical reaction [9]. At the 10th cycle the voltammogram seems to be stabilised with 

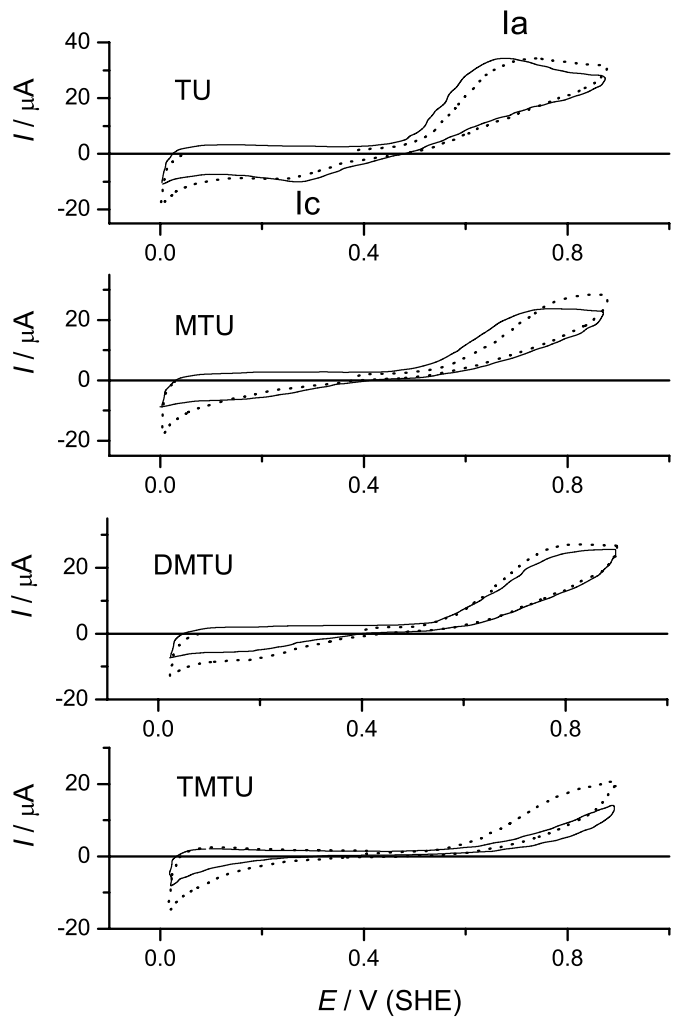

Fig. 2. First (dotted line) and stabilised (full line) voltammograms of platinum run at $v=0.05 \mathrm{~V} \mathrm{~s}^{-1}$ between 0.05 and $0.9 \mathrm{~V}$. Starting potential $=0.4 \mathrm{~V} .1 \mathrm{mM}$ TUs $+0.5 \mathrm{M}$ sulphuric acid, $298 \mathrm{~K}$.

slight shifts of peak Ia to less positive potentials and peak Ic to less negative potentials, as compared to the very first cycle.

For MTU-containing solution, the first positive potential scan shows also peaks Ia/Ic, although significantly less defined (Fig. 2(b)). Compared to TU, the overall voltammogram shows an appreciable inhibition of both the electro-oxidation and the electroreduction processes. Peak Ic appears overlapping a cathodic limiting current that extends from $0.2 \mathrm{~V}$ downwards. The 10th potential cycle results in a stabilised profile with a potential shift of peaks Ia/Ic similar to that found for TU. In this case, $q_{\mathrm{a}} \simeq 475 \mu \mathrm{Ccm}^{-2}$ and $q_{\mathrm{c}} \simeq$ $97.5 \mu \mathrm{C} \mathrm{cm}^{-2}$.

The voltammogram for DMTU (Fig. 2(c)) is largely comparable to that of MTU although it exhibits an increasing inhibition effect, particularly for the electroreduction reactions. In this case, $q_{\mathrm{a}} \simeq 472 \mu \mathrm{C} \mathrm{cm}^{-2}$ and $q_{\mathrm{c}} \simeq 73 \mu \mathrm{C} \mathrm{cm}^{-2}$.

The voltammetric behaviour of TMTU (Fig. 2(d)) involves a higher irreversibility than those of the voltammograms described above. In this case, $q_{\mathrm{a}} \simeq 110 \mu \mathrm{C} \mathrm{cm}^{-2}$ and $q_{\mathrm{c}} \simeq 30 \mu \mathrm{Ccm}^{-2}$. For the case of TMTU, as the potential cycling increases, the voltammetric current decrease gradually to attain a stable profile after ca. 15 cycles.
From Fig. 2(a)-(d), the voltammetric charge ratios are $q_{\mathrm{a}} / q_{\mathrm{c}}=4.54$ for TU, 4.87 for MTU, 6.5 for DMTU and 3.6 for TMTU. These figures are consistent with a decrease in the amount of soluble electro-oxidation products on going from TU to TMTU, and an increase in the inhibition process as the size of the molecule increases. For the case of TMTU, this effect is consistent with the fact that the molecule is apparently adsorbed quasi-parallel to the electrode surface [25].

The above voltammetric description changes drastically when the potential cycling is continued for a couple of hours under strong nitrogen bubbling. Then, the voltammograms, formerly described as stable, for either MTU, DMTU or TMTU, exhibit a marked change approaching profiles similar to that for TU. Seemingly, this behaviour would indicate either that adsorbed residues resulting from substituted TUs tend to behave in a way almost similar to those produced from TU or that inhibiting species adsorbed on the electrode are progressively removed under such conditions. This trend was confirmed from rotating disc electrode data, as described further on.

\subsection{Rotating disc and ring-disc electrode voltammetry}

Voltammograms run at $v=0.005 \mathrm{~V} \mathrm{~s}^{-1}$ with a platinum RDE in TU-containing solutions are different from those run in quiescent solutions, particularly for the negative potential scan (Fig. 3). Thus, the positive potential scan shows an anodic hump Ia in the range 0.8$0.9 \mathrm{~V}$ and anodic peak IIa at ca. $1.3 \mathrm{~V}$ for TU, MTU and DMTU, and a hump at ca. $1.0 \mathrm{~V}$ for TMTU. The reverse potential scan shows a minimum anodic current at about $1.25-1.3 \mathrm{~V}$ followed by a broad anodic current peak at ca. $0.8-0.9 \mathrm{~V}$ (peak IIIa), its height decreasing in the order $\mathrm{MTU}>\mathrm{TU}>\mathrm{DMTU} \simeq \mathrm{TMTU}$. Accordingly, in all cases, the electrode rotation produces a reactivation of the first electro-oxidation process, which is more significant for TMTU.

For all TUs, the plots of the height of peak IIa versus $\omega^{1 / 2}$ approach a single straight line for $500 \leqslant$ $\omega^{1 / 2} \leqslant 7000 \mathrm{rpm}$ with a positive ordinate for $\omega^{1 / 2}=0$ that is close to $0.05 \mathrm{~mA}$ (Fig. 4). Conversely, the same plot for peak IIIa approaches a straight line that tends to go through the origin of coordinates for $\omega<2000$ rpm. For $\omega>2000 \mathrm{rpm}$, data tend to a second linear portion with a slope lower than the previous one and its extrapolation to $\omega=0$ results in approximately the same current value found for peak IIa. The behaviour of these plots indicates that the main reactions related to peaks IIa and IIIa are diffusion controlled, taking place on a partially blocked surface [26]. This conclusion was confirmed by plotting data from peaks IIa and IIIa as $I^{-1}$ versus $\omega^{-1 / 2}$. In this case, for peak IIa a break in the linear plot was observed at high $\omega$ values, as expected for a blocked surface [26]. Therefore, strongly bound 

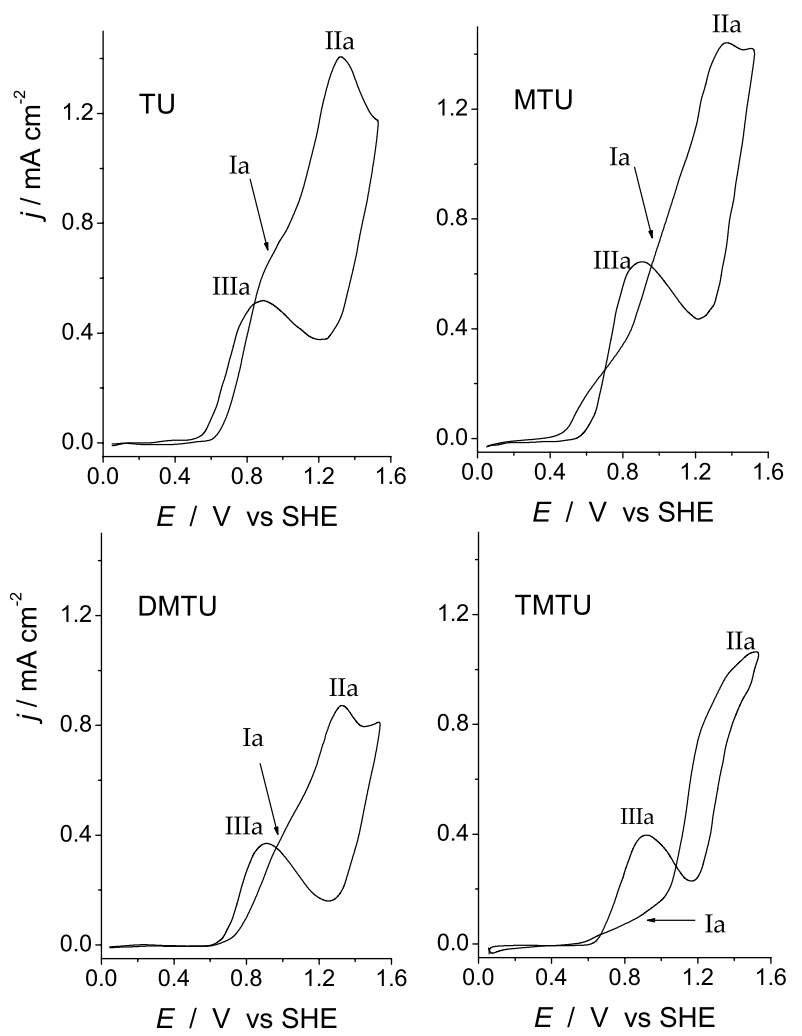

Fig. 3. Rotating disc voltammograms of platinum between 0.05 and $1.6 \mathrm{~V}$ in aqueous $1 \mathrm{mM}$ TUs $+0.5 \mathrm{M}$ sulphuric acid, $v=0.005 \mathrm{~V} \mathrm{~s}^{-1}$; $\omega=7000 \mathrm{rpm}, 298 \mathrm{~K}$.

residues are likely produced from adsorption of TUs at potentials below $0.9 \mathrm{~V}$, and are electro-oxidised at potentials above $1.0 \mathrm{~V}$ [16]. Consequently, the reaction related to peak IIIa starts on an electrode that appears almost free of surface residues. The current values extrapolated for $\omega=0$ (Fig. 4) are consistent with the participation of a stirring-independent electrochemical process.

From the slope of the initial straight line portion for the height of peak IIIa versus $\omega^{1 / 2}$ plot (Fig. 4), an approximate value of the diffusion coefficient $\left(D_{\mathrm{i}}\right)$ of the reactants can be estimated. Thus, for all TUs under comparable voltammetric conditions, using the Levich equation for the RDE assuming that for the initial process the reactant concentration at the electrode surface at the peak potential is that in the bulk of the solution, it results in values of $D_{\mathrm{i}}$ decreasing from $9 \times 10^{-6}$ $\mathrm{cm}^{2} \mathrm{~s}^{-1}$ for TU-MTU to $4 \times 10^{-6} \mathrm{~cm}^{2} \mathrm{~s}^{-1}$ for TMTU. Seemingly, the value of $D_{\mathrm{i}}$ decreases with the solvodynamic radius of the diffusing molecule, as expected.

As the positive potential limit is set to $0.9 \mathrm{~V}$, repetitive cycling of the RDE at $0.05 \mathrm{~V} \mathrm{~s}^{-1}$ and $\omega=2000 \mathrm{rpm}$ results in a progressive increase of $I_{\mathrm{D}}$. The reactivation involves the progressive disappearance of blocking species, this being more marked for TMTU (Fig. 5). In agreement, when stirring is interrupted after, for in-
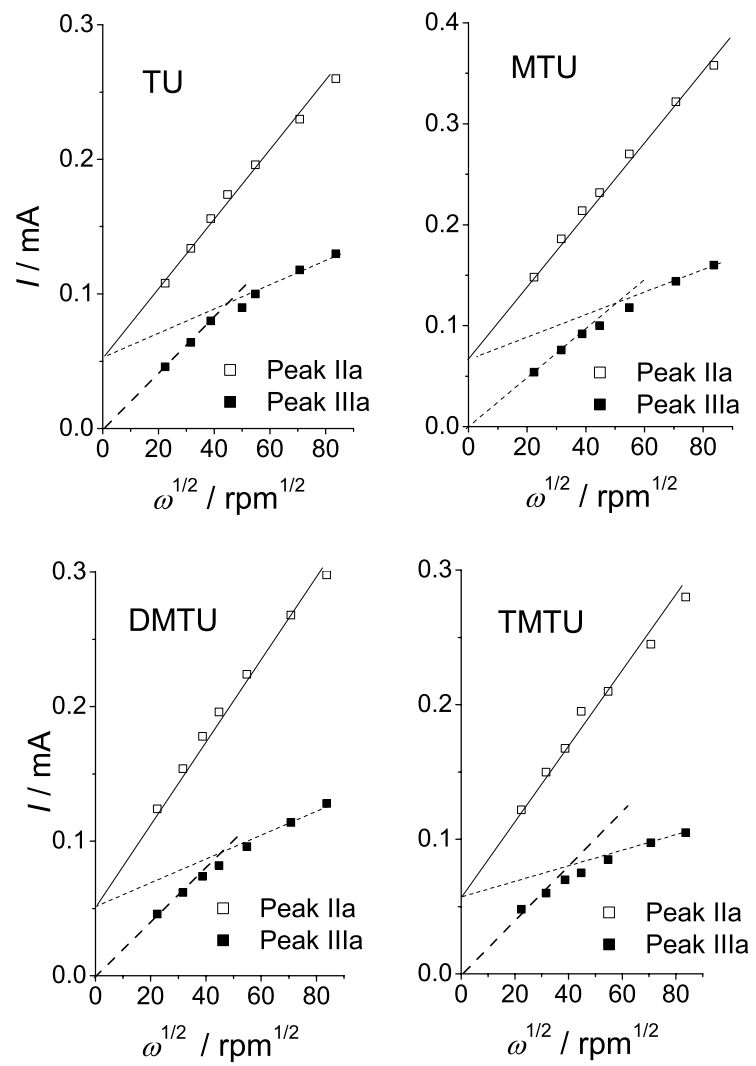

Fig. 4. Dependence of peaks IIa and IIIa on $\omega^{1 / 2}$. Data taken from voltammograms run at $0.005 \mathrm{~V} \mathrm{~s}^{-1}, 298 \mathrm{~K}$.

stance, 20 min cycling, voltammograms resulting from substituted TUs (Fig. 6) approach that of TU (Fig. 2(a)). These results would suggest that similar adsorbed residues are formed on platinum from all TUs by potential cycling in the potential range of the TU/FDS redox couple $(0.05-0.9 \mathrm{~V})$. These results indicate that residues have already begun to appear when the potential is shifted about some hundreds of $\mathrm{mVs}$ either positively or negatively with respect to the equilibrium potentials of different $\mathrm{TU} /$ disulphide redox reactions that lie in the range $0.42-0.46 \mathrm{~V}$ [27].

Soluble products from the first electro-oxidation stage were detected using the RRDE technique in the range $0.05-0.9 \mathrm{~V}$ at $0.05 \mathrm{~V} \mathrm{~s}^{-1}$ and $\omega=2000 \mathrm{rpm}$. For $E_{\mathrm{D}}>0.35 \mathrm{~V}$, the values of both $I_{\mathrm{D}}$ and $I_{\mathrm{R}}$ (Fig. 7) indicate that the amount of soluble products formed anodically decreased in the order TU $>$ MTU $>$ DMTU $>$ TMTU. Accordingly, for $N=0.25$, the $I_{\mathrm{D}} / I_{\mathrm{R}}$ ratio results in 20 for DMTU and MTU, 12 for TU, and 3 for TMTU, i.e., these figures indicate a decrease in the yield of soluble products.

\subsection{FTIRRAS data}

The formation of electro-oxidation products and the corresponding disappearance of reactants from TU, 


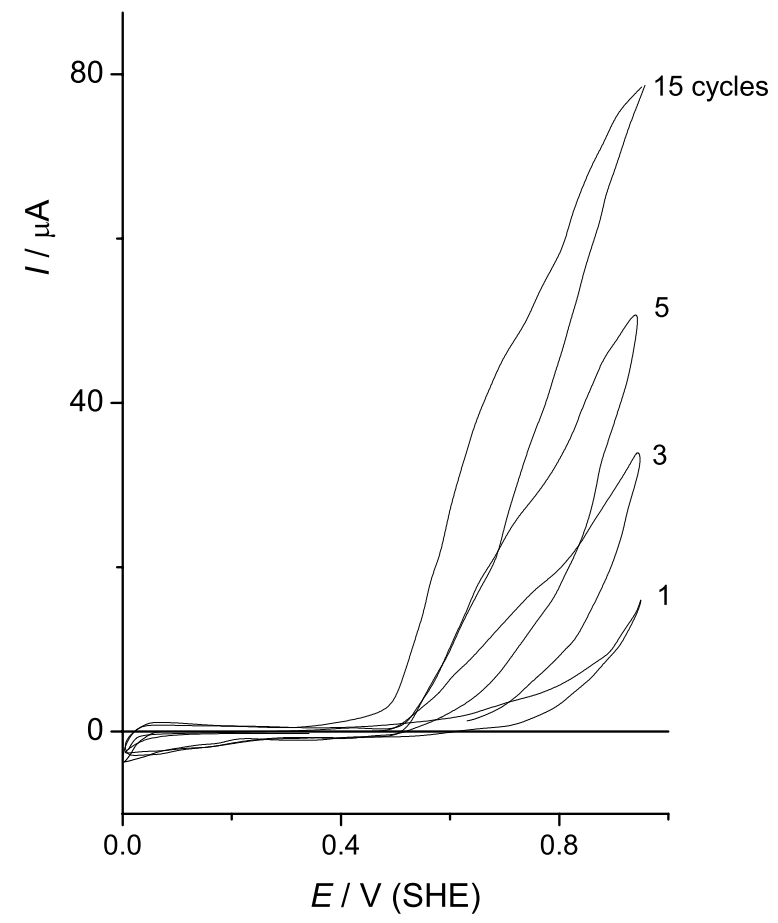

Fig. 5. Repetitive voltammograms of a platinum disc at $v=0.05 \mathrm{~V} \mathrm{~s}^{-1}$ between 0.05 and $0.9 \mathrm{~V}$ under rotation at $\omega=2000 \mathrm{rpm}$ in aqueous $1 \mathrm{mM}$ TMTU $+0.5 \mathrm{M}$ sulphuric acid obtained after decreasing the positive potential limit from 1.55 to $0.9 \mathrm{~V} . v=0.05 \mathrm{~V} \mathrm{~s}^{-1}, 298 \mathrm{~K}$.

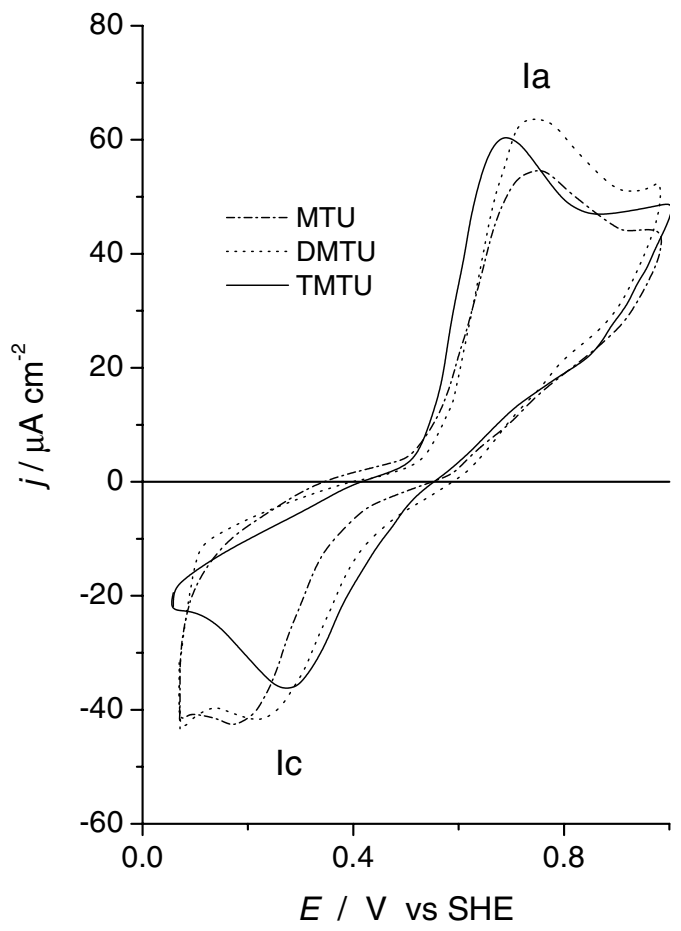

Fig. 6. Voltammograms of a platinum disc run between 0.05 and $0.9 \mathrm{~V}$ in quiescent solution after $20 \mathrm{~min}$ cycling in the same solution under rotation at $\omega=2000 \mathrm{rpm}$. Aqueous $1 \mathrm{mM}$ TUs $+0.5 \mathrm{M}$ sulphuric acid, $v=0.05 \mathrm{~V} \mathrm{~s}^{-1}, 298 \mathrm{~K}$.
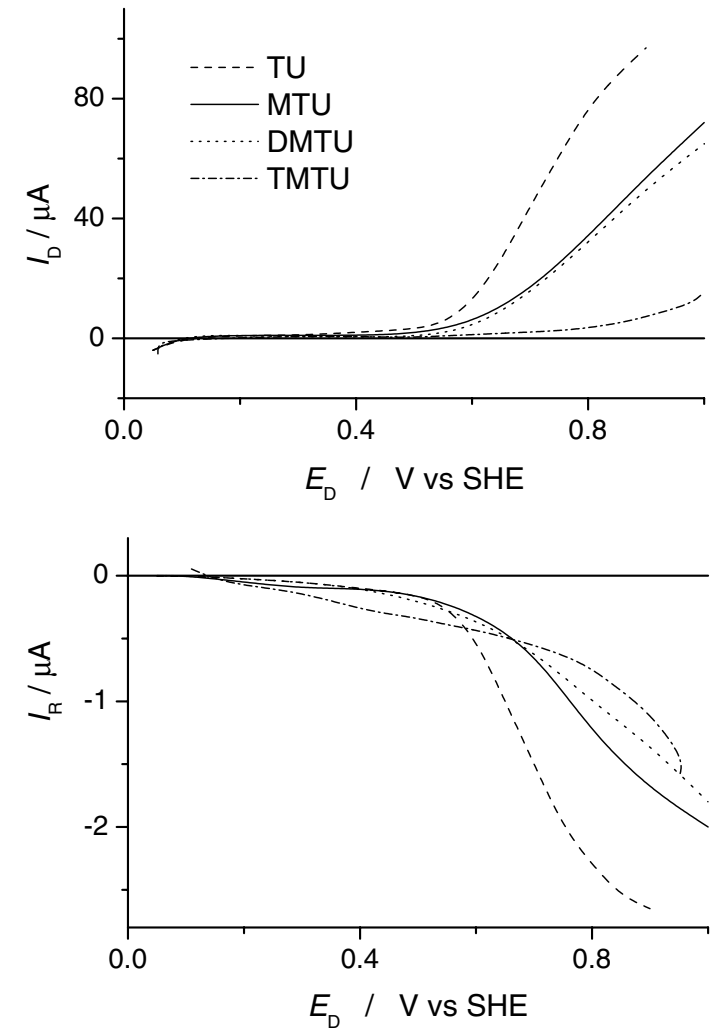

Fig. 7. Rotating ring-disc voltammograms of platinum between 0.05 and $0.9 \mathrm{~V}$ in aqueous $1 \mathrm{mM}$ TUs $+0.5 \mathrm{M}$ sulphuric acid. Disc electrode area $0.25 \mathrm{~cm}^{2} . E_{\mathrm{R}}=0.15 \mathrm{~V}, v=0.05 \mathrm{~V} \mathrm{~s}^{-1} ; \omega=2000 \mathrm{rpm}, 298 \mathrm{~K}$.

MTU, DMTU and TMTU in the range 0.1-1.6 V were followed by in situ FTIRRAS. Both $p$ - and $s$-polarised spectra in the range $1000-2500 \mathrm{~cm}^{-1}$ exhibited the same bands, indicating that all the spectral changes were related to changes in the concentration of species in the thin solution layer. Spectra were collected from 0.1 to $1.6 \mathrm{~V}$, but only a subset of $p$-polarised spectra is shown for clarity. The principal infrared absorption bands of different TUs and FDS are assembled in Tables 1-3.

\subsubsection{TU-containing solutions}

The $p$-polarised spectra from the electro-oxidation of TU in the range $0.6-1.6 \mathrm{~V}$ (Fig. 8) resemble to some extent those reported for TU on platinum in aqueous sodium chloride solutions [28]. As expected from the above electrochemical data, changes in both the number and intensity of negative and positive bands can be distinguished from $E=0.5 \mathrm{~V}$ upwards. The positive bands at 1402 and $1481 \mathrm{~cm}^{-1}$, their intensity increasing with $E$, correspond to the disappearance of TU from the interface. The band at $1402 \mathrm{~cm}^{-1}$ has been assigned to symmetric $\mathrm{N}-\mathrm{C}-\mathrm{N}$ and $\mathrm{C}-\mathrm{S}$ bond stretching, and $\mathrm{NH}_{2}$ rocking modes $[11,28,29]$, while the band at $1481 \mathrm{~cm}^{-1}$ corresponds to the asymmetric $\mathrm{C}-\mathrm{N}$ stretching and $\mathrm{NH}_{2}$ bending modes [11,28,29]. 
Table 1

Principal infrared bands of TU, MTU, DMTU and TMTU

\begin{tabular}{|c|c|c|c|c|c|c|c|}
\hline \multicolumn{2}{|c|}{ TU $[29,45-47]$} & \multicolumn{2}{|l|}{ MTU [48] } & \multicolumn{2}{|c|}{ DMTU $[49,50]$} & \multicolumn{2}{|l|}{ TMTU [51] } \\
\hline $\begin{array}{l}\text { Frequency/ } \\
\mathrm{cm}^{-1}\end{array}$ & Assignment & $\begin{array}{l}\text { Frequency/ } \\
\mathrm{cm}^{-1}\end{array}$ & Assignment & $\begin{array}{l}\text { Frequency/ } \\
\mathrm{cm}^{-1}\end{array}$ & Assignment & Frequency $/ \mathrm{cm}^{-1}$ & Assignment \\
\hline 1040 & $\begin{array}{l}\rho \mathrm{NH}_{2} \\
v_{\mathrm{a}} \mathrm{CN}_{2}\end{array}$ & $1124 \mathrm{~s}$ & $v \mathrm{NCH}_{3}$, & 1038 & $\delta \mathrm{NCN}, v \mathrm{CN}$ & $1096 \mathrm{~s}$ & $\rho \mathrm{CH}_{3}, v_{\mathrm{a}} \mathrm{NCN}$ \\
\hline $1083 \mathrm{~s}$ & $\begin{array}{l}\rho \mathrm{NH}_{2} \\
v_{\mathrm{s}} \mathrm{CN}_{2}\end{array}$ & $1149 \mathrm{~s}$ & $\delta_{r} \mathrm{CH}_{3}$ & 1082 & $\rho \mathrm{CH}_{3}$ & $1119 \mathrm{~s}$ & $\rho \mathrm{CH}_{3}, v \mathrm{NCN}$ \\
\hline $1086 \mathrm{~m}$ & $\rho \mathrm{NH}$ & $1258 w$ & $\delta \mathrm{NH}$ & 1287 & $v \mathrm{CS}$ & $1131 \mathrm{~s}$ & $\rho \mathrm{CH}_{3}$ \\
\hline $1407 \mathrm{~s}$ & $v \mathrm{CS}, v \mathrm{CN}$ & $1297 \mathrm{vs}$ & $\delta \mathrm{NH}, v \mathrm{CN}$ & 1358 & $\delta \mathrm{CH}_{3}$ & $1150 \mathrm{~m}$ & $\delta_{\mathrm{a}} \mathrm{CH}_{3} \mathrm{NC}, \delta_{\mathrm{a}} \mathrm{CH}_{3} \mathrm{NCH}_{3}$ \\
\hline $1413 v s$ & $\begin{array}{l}v \mathrm{CN}_{2}, \\
\rho \mathrm{NH}_{2}, v \mathrm{CS}\end{array}$ & $1404 \mathrm{~s}$ & $\delta_{\mathrm{s}} \mathrm{CH}_{3}$ & 1420 & $\delta \mathrm{NH}, \nu \mathrm{CN}$ & $1208 \mathrm{~m}$ & $\rho \mathrm{CH}_{3}, v_{\mathrm{as}} \mathrm{CH}_{3}-\mathrm{N}, v_{\mathrm{as}} \mathrm{NCN}$ \\
\hline $1413 \mathrm{~s}$ & $v \mathrm{CS}$ & $1454 \mathrm{~s}$ & $\delta_{\mathrm{a}} \mathrm{CH}_{3}$ & 1446 & $\delta \mathrm{CH}_{3}$ & $1262 \mathrm{~s}$ & $v_{\mathrm{s}} \mathrm{CH}_{3} \mathrm{~N}, v_{\mathrm{s}} \mathrm{NCN}, \rho \mathrm{CH}_{3}$ \\
\hline $1470 \mathrm{~s}$ & $v \mathrm{CS}, v \mathrm{CN}$ & $1489 \mathrm{~s}$ & $\delta \mathrm{NH}, v \mathrm{CN}$ & 1506 & $v \mathrm{CS}, \delta \mathrm{NH}$ & $1360 \mathrm{vs}$ & $v_{\text {as }} \mathrm{NCH}_{3}, \delta \mathrm{CH}_{3}$ \\
\hline $1472 \mathrm{vs}$ & $\begin{array}{l}v_{\text {as }} \mathrm{CN}_{2} \\
\delta \mathrm{NH}_{2}\end{array}$ & $1556 \mathrm{vs}$ & $v \mathrm{CN}, \delta \mathrm{NH}$ & 1568 & $v \mathrm{CN}, \delta \mathrm{NH}$ & $1369 \mathrm{~s}$ & $\delta \mathrm{CH}_{3}, v_{\mathrm{as}} \mathrm{NCN}, v_{\mathrm{as}} \mathrm{NCH}_{3}$ \\
\hline $1473 \mathrm{~s}$ & $v \mathrm{CN}$ & $1627 \mathrm{~s}$ & $\delta \mathrm{NH}_{2}$ & & & $1403 \mathrm{~m}$ & $\delta_{\mathrm{a}} \mathrm{CH}_{3} \mathrm{NC}, \delta_{\mathrm{a}} \mathrm{CH}_{3} \mathrm{NCCH}_{3}$ \\
\hline $1588 v s$ & $\begin{array}{l}\delta \mathrm{NH}_{2} \\
v_{\mathrm{as}} \mathrm{CN}_{2}\end{array}$ & $1637 \mathrm{~s}$ & $\delta \mathrm{NH}_{2}$ & & & $1433 \mathrm{~m}$ & $v \mathrm{CS}, \delta_{\mathrm{s}} \mathrm{CH}_{3} \mathrm{NC}, v_{\mathrm{a}} \mathrm{CH}_{3} \mathrm{~N}$ \\
\hline $1612 \mathrm{vs}$ & $\delta \mathrm{NH}_{2}$ & & & & & $1440 \mathrm{~m}$ & $\delta_{\mathrm{a}} \mathrm{CH}_{3}$ \\
\hline $1615 \mathrm{~s}$ & $\delta \mathrm{NH}_{2}$ & & & & & $1470 \mathrm{~m}$ & $\delta_{\mathrm{a}} \mathrm{CH}_{3}$ \\
\hline $1617 \mathrm{~s}$ & $\delta \mathrm{NH}_{2}$ & & & & & $1490 \mathrm{~m}$ & $\begin{array}{l}\delta \mathrm{CH}_{3}, \delta_{\mathrm{a}} \mathrm{CH}_{3} \mathrm{NC}, \\
\delta_{\mathrm{a}} \mathrm{CH}_{3} \mathrm{NCH}_{3}\end{array}$ \\
\hline & & & & & & $1508 \mathrm{~s}$ & $v_{\mathrm{s}} \mathrm{CN}, \rho \mathrm{CH}_{3}, v \mathrm{CS}$ \\
\hline
\end{tabular}

Table 2

Principal infrared bands of FDS from [29]

\begin{tabular}{ll}
\hline Frequency $/ \mathrm{cm}^{-1}$ & Assignment \\
\hline 1055 & $\rho \mathrm{NH}_{2}, v_{\mathrm{as}} \mathrm{CN}_{2}$ \\
$1095 \mathrm{~ms}$ & $\rho \mathrm{NH}_{2}, v_{\mathrm{s}} \mathrm{CN}_{2}$ \\
$1400 \mathrm{vs}$ & $v_{\mathrm{s}} \mathrm{NCN}, \rho \mathrm{NH}_{2}, v \mathrm{CS}$ \\
$1585 \mathrm{vs}$ & $\delta \mathrm{NH}_{2}, v_{\mathrm{as}} \mathrm{CN}_{2}$ \\
$1630 \mathrm{~m}$ & $\delta \mathrm{NH}_{2}, v_{\mathrm{as}} \mathrm{CN}_{2}$ \\
$1654 \mathrm{vs}$ & $\delta \mathrm{NH}_{2}$ \\
\hline
\end{tabular}

Table 3

Principal infrared bands of deuterated TU [14] and FDS [28]

\begin{tabular}{lll}
\hline Frequency $/ \mathrm{cm}^{-1}$ & Assignment & Reference \\
\hline $1390(\mathrm{TU})$ & $v_{\mathrm{s}} \mathrm{CN}_{2}$ & {$[14]$} \\
$1474(\mathrm{TU})$ & $v_{\mathrm{as}} \mathrm{CN}_{2}$ & {$[14]$} \\
$1190(\mathrm{TU})$ & $\delta \mathrm{ND}_{2}$ & {$[14]$} \\
$1140(\mathrm{TU})$ & $\delta \mathrm{ND}_{2}$ & {$[14]$} \\
$1131(\mathrm{TU})$ & $\delta \mathrm{ND}_{2}$ & {$[52]$} \\
$1284(\mathrm{TU})$ & $\delta \mathrm{ND}_{2}$ & {$[52]$} \\
$1355(\mathrm{TU})$ & $v_{\mathrm{s}} \mathrm{CN}$ & {$[52]$} \\
$1449(\mathrm{TU})$ & $v_{\mathrm{as}} \mathrm{CN}$ & {$[52]$} \\
$1388(\mathrm{TU})$ & $\delta \mathrm{ND}_{2}$ & {$[36]$} \\
$1507(\mathrm{TU})$ & $\delta \mathrm{ND}_{2}$ & {$[36]$} \\
& & \\
$1399(\mathrm{FDS})$ & & {$[28]$} \\
1631 (FDS) & & {$[28]$} \\
\hline
\end{tabular}

The complex negative bands in the region of 1600 $\mathrm{cm}^{-1}$ can be considered as the contribution of two overlapping bands located at ca. 1644 and $1665 \mathrm{~cm}^{-1}$. The first one can be assigned to the $\mathrm{OH}$ bending of water molecules and the second one to the bending of

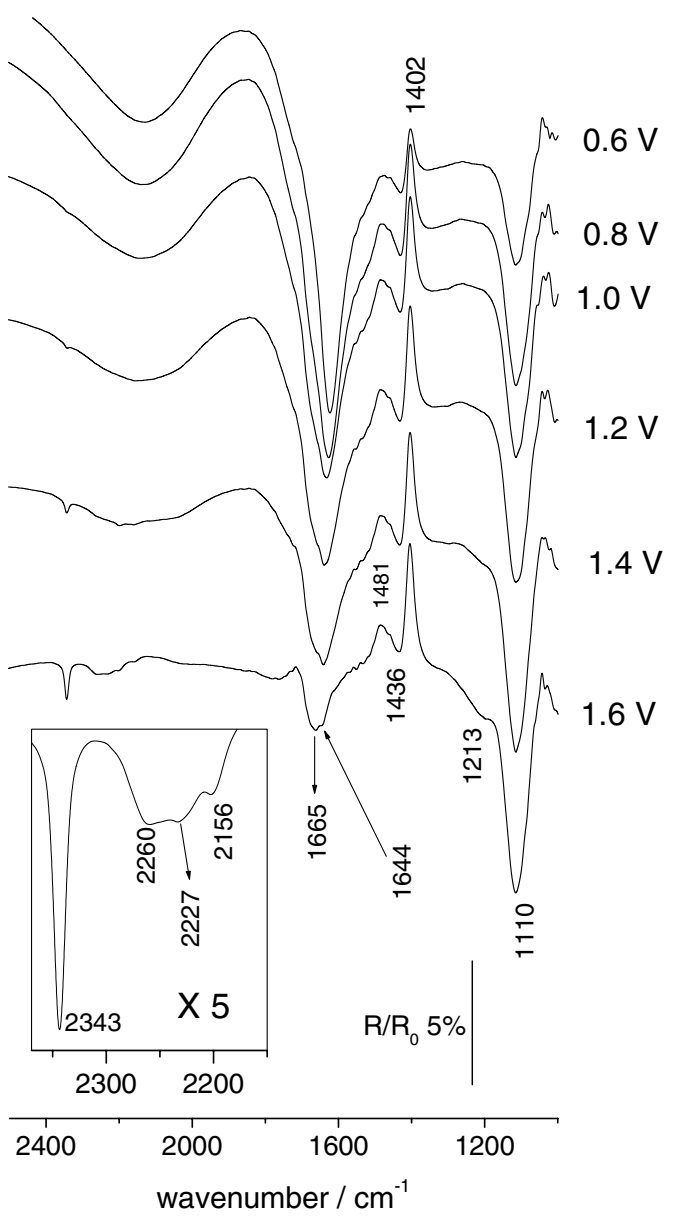

Fig. 8. $p$-Polarised FTIRRAS spectra of platinum in aqueous $0.1 \mathrm{M}$ $\mathrm{TU}+0.1 \mathrm{M}$ perchloric acid at different sampling potentials, $E_{\mathrm{ref}}=$ $0.05 \mathrm{~V}$. 
the $\mathrm{NH}_{2}$ group in the FDS molecule [28,29], the major soluble product from the first TU electro-oxidation stage $[9,24]$. This is, however, a tentative assignment because of the interference of the water molecule bending. For a definite identification of FDS absorption bands, spectra in deuterium oxide solutions were recorded as described later on.

For $E>1.2 \mathrm{~V}$, the complex negative bands at 1644 and $1665 \mathrm{~cm}^{-1}$ decrease and the positive band at $1402 \mathrm{~cm}^{-1}$ increases. Simultaneously, a new negative band appears at $2343 \mathrm{~cm}^{-1}$ its intensity increasing with $E$. This band is related to the asymmetric stretching of $\mathrm{CO}_{2}$ [30] indicating that this molecule is produced from TU electro-oxidation for $E>1.0 \mathrm{~V}$. The detection of carbon dioxide as an electro-oxidation product is at variance with data previously reported for TU electrooxidation on platinum in sodium chloride solution [28].

From $E \geqslant 1.4 \mathrm{~V}$, a new ill-defined negative band appears at ca. $1213 \mathrm{~cm}^{-1}$ due to the formation of bisulphate ions [31]. The absorption band of sulphate ions should appear at $1120 \mathrm{~cm}^{-1}$ but, in this case, it is overlapped by the strong band at $1110 \mathrm{~cm}^{-1}$ corresponding to perchlorate ions, which is observed in all the spectra of TUs described later on. As $E$ is made more positive, migration of perchlorate ions towards the electrode becomes more important and therefore the contribution of perchlorate ions to this complex band increases. At the same time, the local acidification caused by anodisation modifies the sulphate/bisulphate concentration ratio at the thin layer of solution.

Besides, for $E \geqslant 1.4 \mathrm{~V}$ three small negative bands at 2156, 2227 and $2260 \mathrm{~cm}^{-1}$ can be seen (Fig. 8 inset). These bands appear in the region where the stretching of $\mathrm{C} \equiv \mathrm{N}$ bonds is usually observed [32]. In fact, cyanamide has been reported as a product of TU electro-oxidation on platinum [28]. Pure cyanamide shows the $\mathrm{CN}$ stretching at $2280 \mathrm{~cm}^{-1}$ [33]. On the other hand, nitriles easily hydrolyse in acid yielding the corresponding amide. The formation of the latter results in the presence of a negative band at ca. $1660 \mathrm{~cm}^{-1}$ due to the $\mathrm{C}=\mathrm{O}$ stretching [34]. In our case, the identification of this band is obscured by those bands corresponding to water and FDS in this range of the spectra.

Spectra in deuterium oxide and sulphuric acid solution were recorded to minimise the interference of water. It should be noted that TU and FDS undergo an isotopic exchange in deuterated acid solutions [35], resulting in a shift of the main absorption bands. Consequently, absorption bands for deuterated TU appear at 1388 and $1519 \mathrm{~cm}^{-1}[28,36]$, and for deuterated FDS at 1399 and $1631 \mathrm{~cm}^{-1}$ [28].

The $p$-polarised spectra recorded during the electrooxidation of TU from 0.6 to $1.6 \mathrm{~V}$ (Fig. 9) show positive bands at 1385 and $1518 \mathrm{~cm}^{-1}$, and negative bands at 1110, 1180, 1263, 1402 and $1634 \mathrm{~cm}^{-1}$. Bipolar bands are defined by the pairs of peaks at $1385 / 1402 \mathrm{~cm}^{-1}$ and

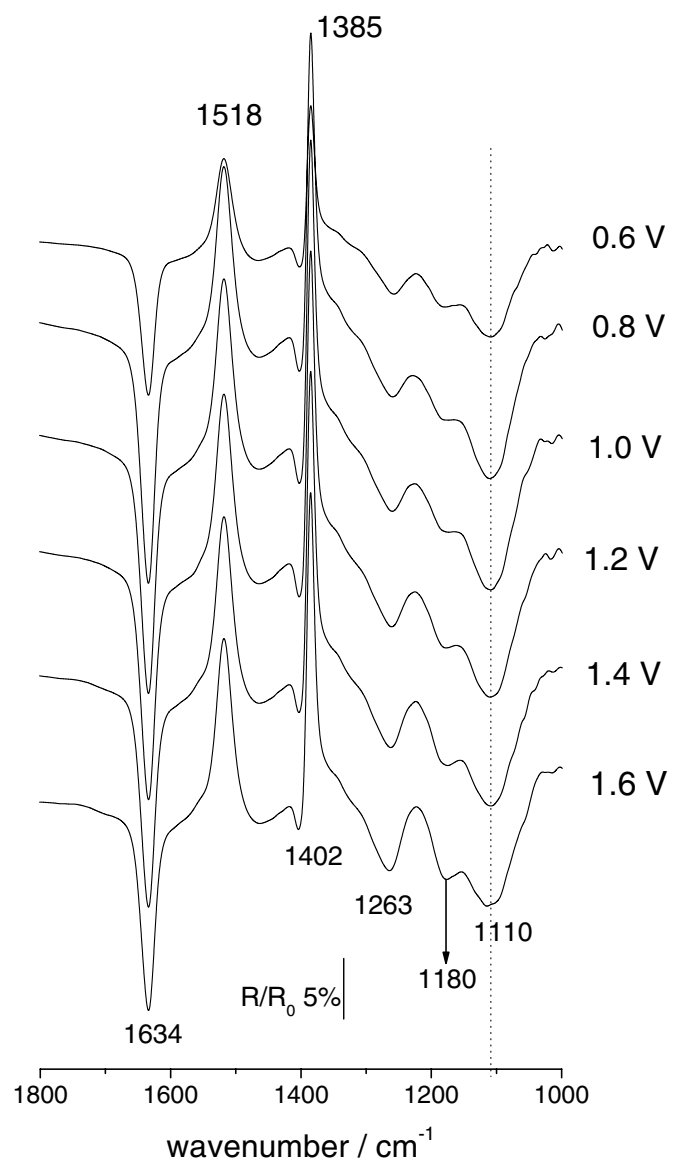

Fig. 9. $p$-Polarised FTIRRAS spectra of platinum in $0.1 \mathrm{M} \mathrm{TU}+0.1 \mathrm{M}$ sulphuric acid deuterium oxide at different sampling potentials, $E_{\text {ref }}=0.05 \mathrm{~V}$.

$1518 / 1634 \mathrm{~cm}^{-1}$. The positive bands at 1385 and 1518 $\mathrm{cm}^{-1}$ are assigned to the depletion of deuterated TU, and the negative bands at 1402 and $1634 \mathrm{~cm}^{-1}$ to the appearance of deuterated FDS [28]. These bands can already be seen from $E=0.5 \mathrm{~V}$ upwards. The low intensity of the negative band at $1402 \mathrm{~cm}^{-1}$ is probably caused by the increase of the TU band at $1385 \mathrm{~cm}^{-1}$. Negative bands at 1110,1180 and $1263 \mathrm{~cm}^{-1}$ are related to the presence of sulphate/bisulphate ions at the interface from the base electrolyte solution and from the electro-oxidation of TU.

\subsubsection{MTU-containing solutions}

The $p$-polarised spectrum from the electro-oxidation of MTU recorded at $0.6 \mathrm{~V}$ (Fig. 10) shows positive bands at 1302, 1399, 1475, 1558 and $1694 \mathrm{~cm}^{-1}$, and negative bands at $1100,1424,1520$ and $1606 \mathrm{~cm}^{-1}$, the intensity of all bands increasing with $E$. The change in the intensity of the positive bands agrees with the progressive disappearance of MTU as $E$ is increased positively. These bands are assigned to $\mathrm{NH}$ deformation $\left(1302 \mathrm{~cm}^{-1}\right)$ and $\mathrm{CN}$ stretching $\left(1563 \mathrm{~cm}^{-1}\right)$, and to $\mathrm{CH}_{3}$ deformation (1399 and $1475 \mathrm{~cm}^{-1}$ ) (Table 1). 


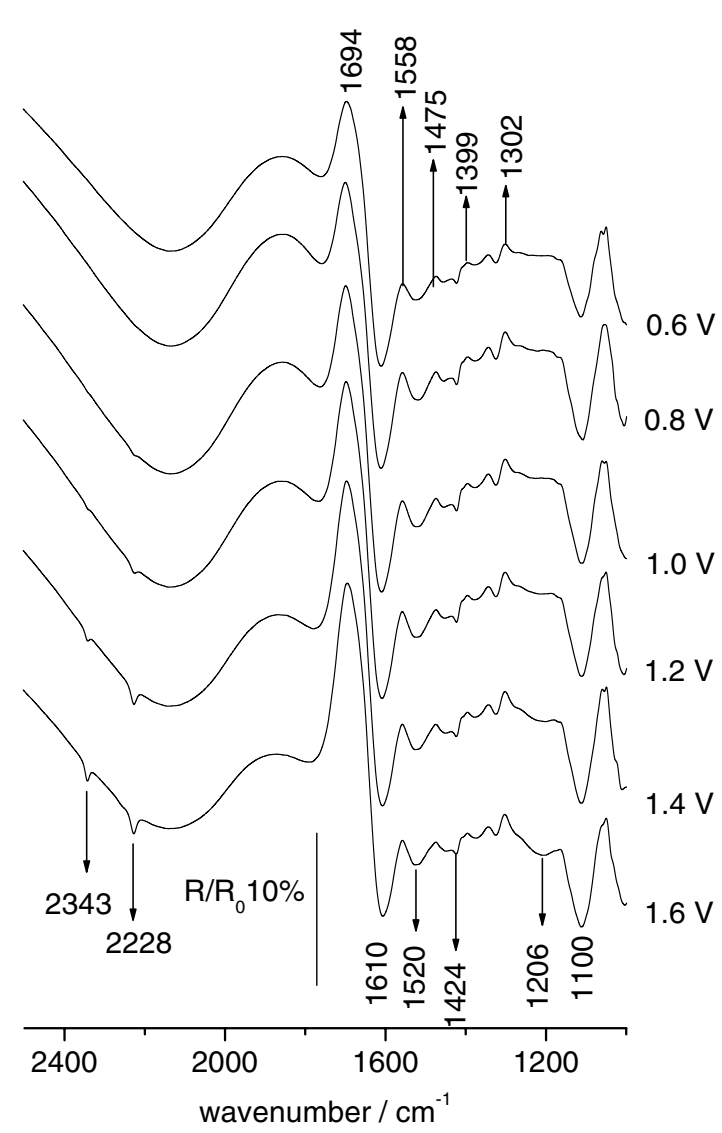

Fig. 10. $p$-Polarised FTIRRAS spectra of platinum in aqueous $0.1 \mathrm{M}$ $\mathrm{MTU}+0.1 \mathrm{M}$ perchloric acid at different sampling potentials, $E_{\text {ref }}=0.05 \mathrm{~V}$.

Negative bands appear at 1424 and $1606 \mathrm{~cm}^{-1}$. The latter is red-shifted with respect to that corresponding to unsubstituted FDS, which appears at $1650 \mathrm{~cm}^{-1}[28,37]$. Presumably, these bands are related to the influence of the N-substitution disulphide bond on the NH deformation and $\mathrm{CN}$ stretching modes in the molecule.

From $0.8 \mathrm{~V}$ upwards, the intensity of the negative band at $2228 \mathrm{~cm}^{-1}$ begins to increase. This band can be assigned to the $\mathrm{C} \equiv \mathrm{N}$ stretching mode that is expected from the formation of cyanamide [28,33]. At variance with $\mathrm{TU}$, this band is very sharp and free of satellite bands. For $E>1.2 \mathrm{~V}$, a negative band related to the $\mathrm{CO}_{2}$ asymmetric stretching [30] at $2343 \mathrm{~cm}^{-1}$, and for $E>1.4 \mathrm{~V}$, a broad negative band at $1206 \mathrm{~cm}^{-1}$ related to the formation of bisulphate species are recorded. As for the case of TU, the negative band at $1100 \mathrm{~cm}^{-1}$ due to the presence of perchlorate ions is also observed, the intensity of this band increasing with $E$ as expected.

\subsubsection{DMTU-containing solutions}

As compared to spectra of the previous TUs, those resulting from DMTU-containing solution (Fig. 11) exhibit significant changes from $0.5 \mathrm{~V}$ upwards. At $0.6 \mathrm{~V}$, a series of positive-going bands that correspond

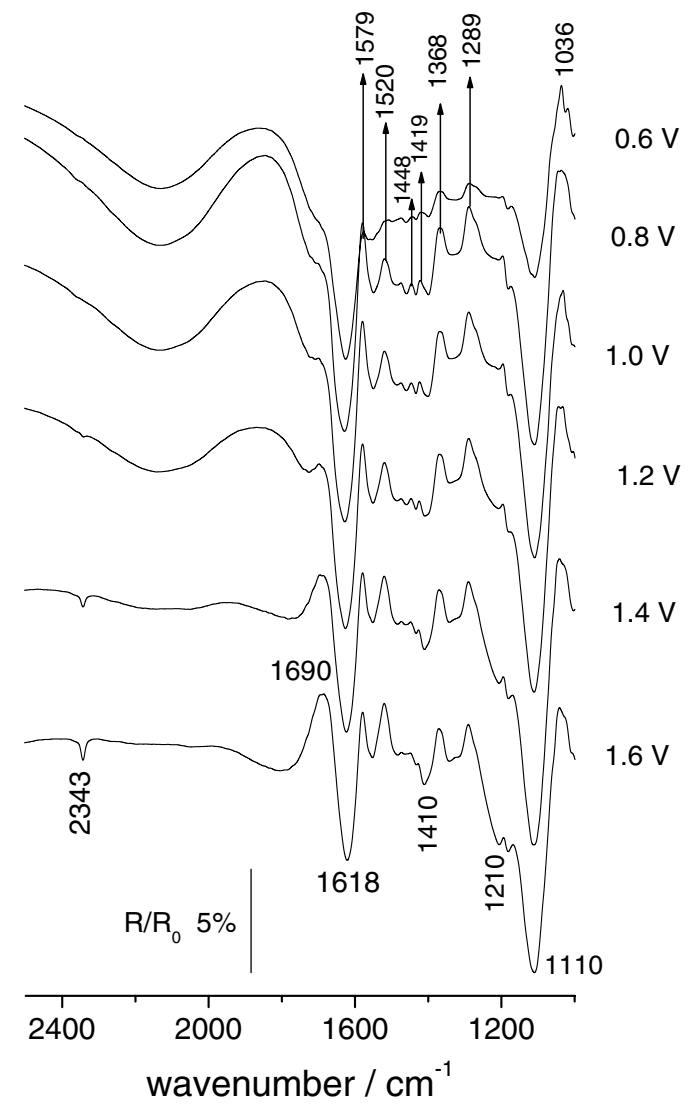

Fig. 11. $p$-Polarised spectra at different $E_{\mathrm{s}}$ values. Platinum in aqueous $0.1 \mathrm{M} \mathrm{DMTU}+0.1 \mathrm{M}$ perchloric acid, $E_{\text {ref }}=0.05 \mathrm{~V}$.

to the depletion of DMTU (Table 1) in the thin solution layer is observed.

The negative band that appears at $1110 \mathrm{~cm}^{-1}$ is due to migration of perchlorate ions. The band at $1620 \mathrm{~cm}^{-1}$ decreases for $E>1.1 \mathrm{~V}$, i.e., concomitantly with the occurrence of a new positive band at $1690 \mathrm{~cm}^{-1}$ that increases with $E$. From $1.2 \mathrm{~V}$ upwards, three new negative bands at 1210,1410 and $2343 \mathrm{~cm}^{-1}$ are observed. The first one can be assigned to the appearance of bisulphate ions from the protonation of sulphate ions coming from DMTU electro-oxidation. The band at $2343 \mathrm{~cm}^{-1}$ is related to the formation of carbon dioxide. The appearance of a negative band at $1410 \mathrm{~cm}^{-1}$ might be related to the formation of the corresponding disulphide.

In contrast to TU and MTU, the absence of a band at ca. $2230 \mathrm{~cm}^{-1}$ would indicate that in the electro-oxidation of DMTU no CN-containing product is formed. Seemingly, the presence of $\mathrm{CH}_{3}$ groups on both $\mathrm{N}$ atoms would prevent the formation of $\mathrm{C} \equiv \mathrm{N}$ bonds.

\subsubsection{TMTU-containing solutions}

The spectra recorded from $0.6 \mathrm{~V}$ upwards (Fig. 12) show positive strong and medium bands whose location 


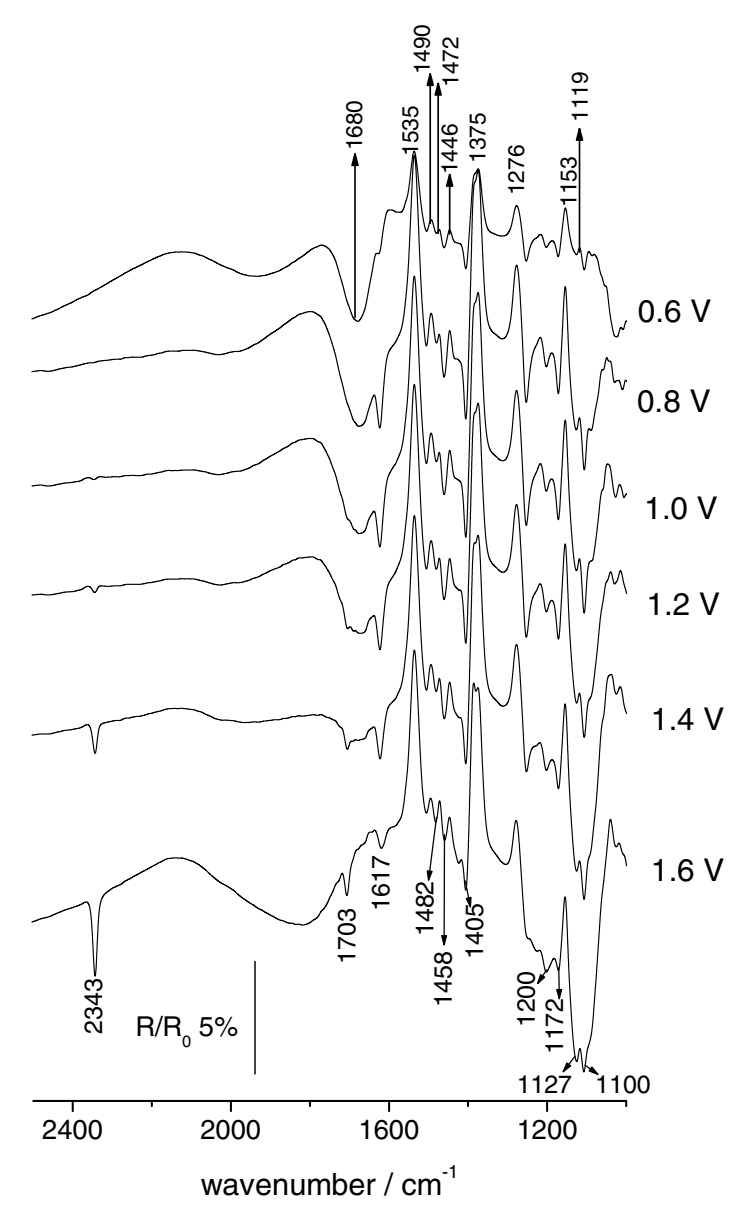

Fig. 12. $p$-Polarised spectra at different $E_{\mathrm{s}}$ values. Platinum in aqueous $0.1 \mathrm{M}$ TMTU $+0.1 \mathrm{M}$ perchloric acid, $E_{\mathrm{ref}}=0.05 \mathrm{~V}$.

and relative intensity are in good agreement with IR data that have been reported for TMTU (Table 1). These spectra indicate the disappearance of TMTU when the potential is increased in the range $0.6 \leqslant E \leqslant$ $1.6 \mathrm{~V}$.

Negative bands observed for $E>0.5 \mathrm{~V}$ at 1405,1458 and $1482 \mathrm{~cm}^{-1}$ together with a hump at $1617 \mathrm{~cm}^{-1}$ are related to the formation of products from TMTU electro-oxidation. All these bands increase as $E$ is shifted positively. At $0.8 \mathrm{~V}$, the negative band at $1617 \mathrm{~cm}^{-1}$ is well defined and increases with $E$. From ca. $1.0 \mathrm{~V}$ upwards, the negative band at $2343 \mathrm{~cm}^{-1}$ due to the formation of carbon dioxide is observed. Its intensity increases with $E$.

For $E>1.15 \mathrm{~V}$, the negative band at $1703 \mathrm{~cm}^{-1}$ coincides with that expected for the stretching band of $\mathrm{C}=\mathrm{O}$ and suggests the formation of a CO-containing product. The intensity of the band at $1703 \mathrm{~cm}^{-1}$ increases with $E$, whereas the height of the negative band at $1617 \mathrm{~cm}^{-1}$ decreases. At $1.6 \mathrm{~V}$, the presence of a negative band at $1200 \mathrm{~cm}^{-1}$ indicates the formation of bisulphate ions coming from the electro-oxidation of sulphur atoms. Furthermore, as referred to in Section 3.4 .2 , negative bands in the range $1400-1630 \mathrm{~cm}^{-1}$ can tentatively be assigned to the formation of the TMTU disulphide species in solution. These results suggest that for $E \geqslant 1.15 \mathrm{~V}$, the partial electro-oxidation of TMTU to $\mathrm{CO}_{2}, \mathrm{H}^{+}$and $\mathrm{SO}_{4}^{2-}$ occurs via disulphide. In agreement with FTIRRAS data for DMTU (Fig. 11), no band related to the formation of cyanamide can be seen in TMTU spectra.

The spectra recorded in $0.1 \mathrm{M}$ sulphuric acid in deuterium oxide (Fig. 13), i.e. without the interference of the strong water band in the $1600 \mathrm{~cm}^{-1}$ range, show the positive bands already identified for TMTU. This result indicates that no isotopic exchange occurs between methyl groups and solvent. At the same time, in comparison to TMTU-containing aqueous solution, no significant change in the location of the negative bands is observed. Taking into account that the bands at 1405 and $1623 \mathrm{~cm}^{-1}$ appear for $E>0.5 \mathrm{~V}$ and are not influenced by the presence of deuterium atoms in the solution, it seems reasonable to assume that they are related to the formation of tetramethylformamidine disulphide, a species that can be produced from the chemical oxidation of TMTU with hydrogen peroxide and is stable in acid solutions [38].

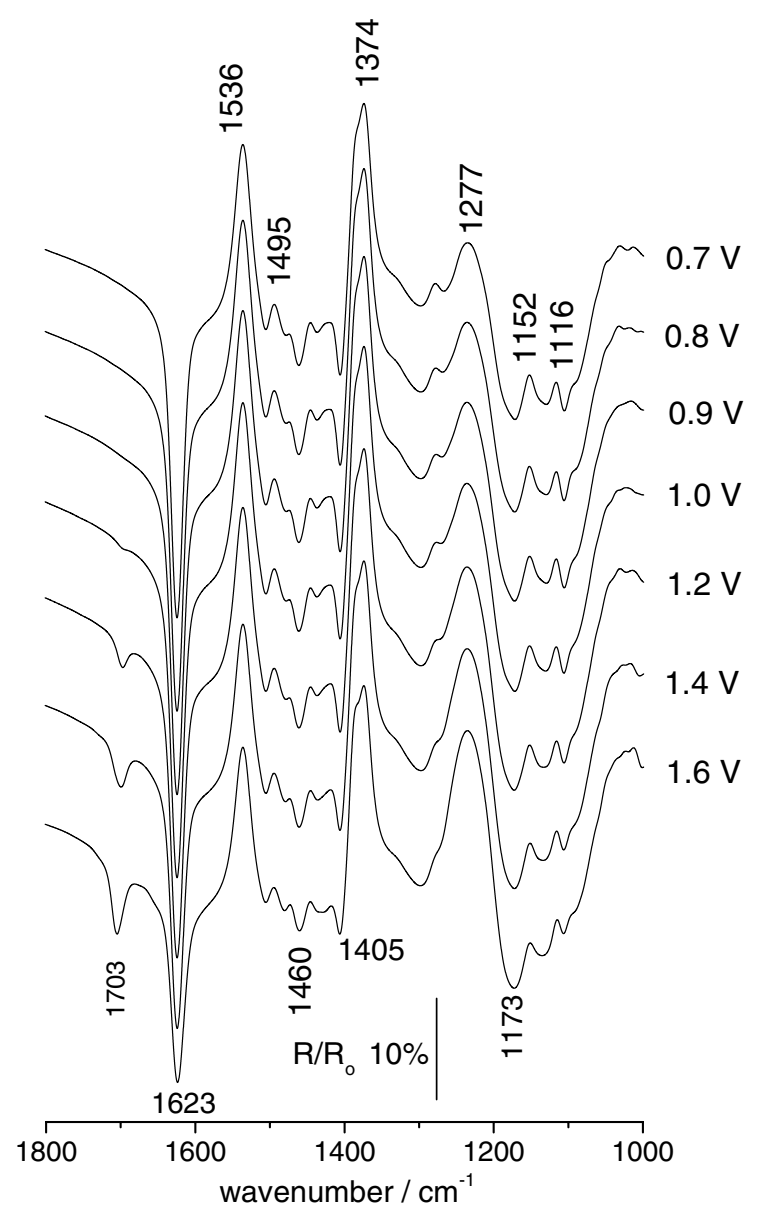

Fig. 13. $p$-Polarised spectra at different $E_{\mathrm{S}}$ values. Platinum in $0.1 \mathrm{M}$ TMTU $+0.1 \mathrm{M}$ sulphuric acid deuterium oxide, $E_{\text {ref }}=0.05 \mathrm{~V}$. 


\section{Discussion}

Voltammetric data from TU-containing solutions show that broadly two potential regions associated with the main electro-oxidation reactions can be distinguished, irrespective of TUs. In the first region that covers the range $0.5-0.9 \mathrm{~V}$, peak Ia is the principal voltammetric feature, mainly associated with the TU/ TU disulphide electrode reaction $[9,24]$. This is in agreement with previous work reporting that TU disulphides are produced in the oxidation of aliphatic TUs [39] and the fact that molecules of TUs are readily adsorbed on platinum producing surface residues that are electro-oxidised at potentials above $0.7 \mathrm{~V}$ [16]. As far as TU disulphides are concerned, the formation of (tetramethyl-formamidine) disulphide has been reported for $\mathrm{OH}$-radical-induced oxidation in aqueous solutions [38]. In this case, the resulting dimeric radical cation involves resonant structures with the formation of $\mathrm{C}=\mathrm{N}$ bonds.

The voltammetric electroreduction of soluble disulphides takes place in the range $0.1-0.5 \mathrm{~V}$ for all TUs, and in all voltammograms the potential of zero current $\left(E_{j=0}\right)$ is equidistant of the anodic and cathodic current peak potentials (Fig. 6) and close to the reversible potential of the TU/FDS redox couples (TU/FDS = $0.42 \mathrm{~V}, \mathrm{MTU} / \mathrm{MFDS}=0.46 \mathrm{~V}$, DETU/DEFDS $=0.45$ $\mathrm{V}$ [27]). These features suggest conjugated electrochemical processes with rather sluggish kinetics.

The second electro-oxidation region in the range 0.9 $1.6 \mathrm{~V}$ is dominated by the appearance of voltammetric peak IIa related to further electro-oxidation of TUs and their disulphides to soluble and insoluble products. This is concluded from FTIRRAS data showing the appearance of products in solution starting at ca. $0.5 \mathrm{~V}$, the formation of only TU disulphide species below $1.0 \mathrm{~V}$ and higher oxidised species such as sulphate ions, cyanamide and carbon dioxide from $1.0 \mathrm{~V}$ upwards. The relative yields of these species depend specifically on each TU, i.e. whether it is non-substituted, monosubstituted or multi-substituted.

\subsection{Reactions in the first electro-oxidation stage}

The threshold potential of the first electro-oxidation stage is very close for all TUs, but the charge resulting from peak Ia depends on the type of TUs, the positive potential limit $E_{\mathrm{u}}$, number of cycles and solution stirring. Thus, when the stabilised voltammogram is run in a quiescent solution covering the range from 0.05 to $1.6 \mathrm{~V}$, the charge of peak Ia is almost the same for all but TMTU (Fig. 1). For the latter, when $E_{\mathrm{u}}$ is decreased to $0.9 \mathrm{~V}$, the charges of peaks Ia and Ic are practically nil (Fig. 2), i.e., the electron transfer is hindered by TMTU residues remaining at the electrode surface.

For all substituted TUs after potential cycling for several minutes in the first electro-oxidation potential range, the voltammetric response tends to reach that of TU. This fact suggests that the first electro-oxidation reaction is progressively inhibited as the substitution in TUs is increased, due to the blockage of the electrode, although the reactivation is slowly recovered by potential cycling. The surface concentration of the inhibiting residues appears to be rather low for substituted TUs at low $E$, and only increases by potential cycling below $0.9 \mathrm{~V}$. This agrees with the fact that on shifting $E_{\mathrm{u}}$ from 0.9 to $1.5 \mathrm{~V}$ peak Ia is again suppressed. Then, for all TUs, as the coverage by residues at the surface reaches a critical value, the first electro-oxidation reaction can be represented by a common reaction formalism yielding soluble disulphides as the main product.

FTIRRAS data are consistent with the interpretation given above. All spectra exhibit bands for the depletion of TUs in the thin solution layer starting from $0.5 \mathrm{~V}$, irrespective of TUs. At the same time, for $E<0.9 \mathrm{~V}$, a band at about $1600 \mathrm{~cm}^{-1}$ due to the formation of the corresponding disulphides is systematically observed. Besides, FTIRRAS data from TU in deuterium oxide confirm the formation of FDS. For the electro-oxidation of TMTU, spectra obtained in deuterium oxide also exhibit negative absorption bands at 1405 and 1623 $\mathrm{cm}^{-1}$ similar to those observed during TU electro-oxidation and related to the formation of tetramethylformamidine disulphide (TFDS) [40].

The similarity of the spectra of the TUs and those of their corresponding formamidine disulphides has been pointed out in previous work for TU and DMTU, although the identification of disulphides was complicated by the similarity of the spectra of FDS and TU, and $\left(N, N^{\prime}\right.$-dimethyl) formamidine disulphide and DMTU [27]. The decrease in the intensity of the band close to $1600 \mathrm{~cm}^{-1}$ when going from TU to TMTU correlates well with the voltammetric response in the range 0.05$0.9 \mathrm{~V}$, which shows that disulphide formation becomes more difficult as the number of hydrogen atoms substituted by $\mathrm{CH}_{3}$ in $\mathrm{TU}$ increases.

The correlation between voltammetric and spectroscopic data suggests that the first electro-oxidation stage of TUs in solution can be represented by a main formal reaction involving the formation of disulphide linkage through an electron transfer such as

$$
\begin{aligned}
2(\mathrm{XYN})\left(\mathrm{XY}^{\prime} \mathrm{N}\right) \mathrm{CS} \rightleftharpoons & {\left[(\mathrm{XYN})_{2} \mathrm{CS}-\mathrm{SC}\left(\mathrm{NXY}^{\prime}\right)_{2}\right] } \\
& +2 \mathrm{H}^{+}+2 \mathrm{e}^{-}
\end{aligned}
$$

yielding a soluble disulphide with $\mathrm{X}=\mathrm{Y}=\mathrm{Y}^{\prime}=\mathrm{H}$ for $\mathrm{TU}, \mathrm{X}=\mathrm{Y}=\mathrm{H}$ and $\mathrm{Y}^{\prime}=\mathrm{CH}_{3}$ for $\mathrm{MTU}, \mathrm{X}=\mathrm{H}$ and $\mathrm{Y}=\mathrm{Y}^{\prime}=\mathrm{CH}_{3}$ for DMTU and $\mathrm{X}=\mathrm{Y}=\mathrm{Y}^{\prime}=\mathrm{CH}_{3}$ for TMTU.

Reaction (1), however, takes place on a platinum surface that is largely covered by adsorbed TUs [16]. The yield of this reaction decreases in the order TU $>$ MTU $>$ DMTU $>$ TMTU, as seen from the height 
of peak Ia and the increasing irreversibility of the voltammetric electroreduction (Fig. 2). This agrees with RRDE data, in the range $0.7 \leqslant E_{\mathrm{D}} \leqslant 0.9 \mathrm{~V}$, where the lowest $I_{\mathrm{D}} / I_{\mathrm{R}}$ ratio at $E_{\mathrm{R}}=0.15 \mathrm{~V}$ is obtained for TMTU. The lower anodic current at $0.8 \mathrm{~V}$ for TMTU indicates that reaction (1) is inhibited either by the presence of TMTU adsorbates or by carbon- and sulphur-containing residues on the electrode surface resulting from the adsorption of TMTU. This would explain why one observes intermediate kinetics and an increasing irreversibility for reaction (1) as the substitution of $\mathrm{H}$ by $\mathrm{CH}_{3}$ increases. The inhibition effect is also concluded by comparing the first and stabilised voltammogram run in the range $0.05-0.9 \mathrm{~V}$ with different TUs (Fig. 2).

The relatively strong TU-metal interaction via $\mathrm{S}$ atoms results in definite potential-dependent adsorption patterns that have been observed with scanning tunnelling microscopy [41]. Accordingly, reaction (1) should be preceded by the spontaneous formation of TU adsorbates that later participate in different electrosorption reactions. Some electroadsorbed species from these reactions would lead to the formation of soluble and insoluble products.

For simplicity, let us consider TU as representative of all TUs. The chemical TU-platinum interaction yielding the $\mathrm{TU}$ adsorbate $\mathrm{TU}_{\mathrm{ad}}$ can be written as follows

$\mathrm{Pt}(\mathrm{s})+\mathrm{TU}(\mathrm{aq}) \rightarrow \operatorname{Pt}(\mathrm{TU})_{\mathrm{ad}}$

that results in electroadsorbed deprotonated $\mathrm{TU}^{*}$ species,

$\mathrm{Pt}(\mathrm{TU})_{\mathrm{ad}} \rightarrow \mathrm{Pt}\left(\mathrm{TU}^{*}\right)_{\mathrm{ad}}+\mathrm{H}^{+}(\mathrm{aq})+\mathrm{e}^{-}$

Reaction (2) would be favoured at $E<E_{\mathrm{pzc}}$, the potential of zero charge of the metal, or assisted by simultaneous anion adsorption at $E>E_{\mathrm{pzc}}$, and reaction (3), in principle, would precede the formation of either blocking or soluble species, respectively. The rate constant of reaction (3) on gold is of the order of $\mathrm{ms}^{-1}$ [42].

The electrode blockage may also occur from FDS formation resulting from the following electrochemical reaction

$$
\begin{aligned}
& \mathrm{Pt}\left(\mathrm{TU}^{*}\right)_{\mathrm{ad}}+\mathrm{TU}(\mathrm{aq})+\mathrm{Pt} \\
& \quad \rightarrow \mathrm{Pt}_{2}(\mathrm{FDS})_{\mathrm{ad}}+\mathrm{H}^{+}(\mathrm{aq})+\mathrm{e}^{-}
\end{aligned}
$$

in which each FDS adsorbate involves two neighbour platinum sites as has been observed on $\mathrm{Au}\left(\begin{array}{lll}1 & 1 & 1\end{array}\right)$ [41].

Conversely, soluble disulphide results from either the desorption of adsorbed FDS

$\mathrm{Pt}_{2}(\mathrm{FDS})_{\mathrm{ad}} \rightleftharpoons 2 \mathrm{Pt}(\mathrm{s})+\mathrm{FDS}(\mathrm{aq})$

or the electrochemical reaction

$$
\begin{aligned}
\mathrm{Pt}\left(\mathrm{TU}^{*}\right)_{\mathrm{ad}}+\mathrm{TU}(\mathrm{aq}) \rightarrow & \mathrm{Pt}(\mathrm{s})+\mathrm{FDS}(\mathrm{aq}) \\
& +\mathrm{H}^{+}(\mathrm{aq})+\mathrm{e}^{-}
\end{aligned}
$$

The formation of soluble disulphide is determined by the diffusion of TU towards the electrode surface, irrespective of electrode blocking, although with a specific current versus $\omega$ response (Fig. 4). The kinetics of the formation of the blocking adsorbate layer do not depend on $\omega$ and can be related to the current read at $\omega=0$ in the $I$ versus $\omega^{1 / 2}$ plots. The rate of the surface blockage should be related to the rate of reaction (2).

On the other hand, according to the experimental results, the electrode surface becomes almost FDS-free for $E>0.9 \mathrm{~V}$ due to the electro-oxidation of FDS. Accordingly, the surface concentration of TU at the interface increases and the reactivation peak IIIa, related to reaction (1), occurs in a situation considerably different from that found for peak IIa.

The above reaction pathway seems to be the same for substituted TUs yielding their corresponding formamidine disulphides.

\subsection{The second electro-oxidation stage}

For the second electro-oxidation stage that occurs from $1.0 \mathrm{~V}$ upwards, voltammograms from different TUs show anodic peak IIa at about $1.2 \mathrm{~V}$ related to further electro-oxidation of the corresponding disulphides yielding soluble products, including oxygencontaining ones. The latter are produced simultaneously with the oxygen-containing layer, from a submonolayer upwards, that is formed on platinum from water discharge [22]. In this case, IR spectra show the formation of different soluble species depending on the type of TU. Nevertheless, in this potential range, all TUs exhibit as common electro-oxidation products, carbon dioxide and sulphate ions, which are related to the bands at 2343 and $1100 \mathrm{~cm}^{-1}$, respectively. Carbon dioxide was recently reported as a product from TU electro-oxidation on gold electrodes at potentials related to the formation of the oxygen-containing layer on gold [37]. Sulphate ions are produced by complete electro-oxidation of TU at high potentials, as was found for both gold [37] and platinum [28] electrodes in acid solutions. Sulphate ions also result from migration into the thin layer of solution due to the local acidification produced by the formation of the oxygen-containing layer on platinum at these potentials [22]. Hydrogen ions from this anodisation process migrate outwards, or are, in part, neutralised by sulphate ion migration inwards [23], favouring bisulphate ion formation, in agreement with the appearance of IR bands at ca. 1050 and $1200 \mathrm{~cm}^{-1}$, particularly as $E$ is increased positively.

The main spectral difference in the second electrooxidation of TUs arises from the bands in the region $2200-2300 \mathrm{~cm}^{-1}$ that are related to the formation of $\mathrm{CN}$-containing species. It is known that cyanamide is a major product in the oxygen-assisted oxidative degra- 
dation of TU $[43,44]$ as has been detected by in situ FTIRRAS during the electro-oxidation of TU on gold [37] and platinum [28]. In the present case, cyanamide or at least $\mathrm{CN}$-containing products are produced only in the case of TU and MTU. It appears that as amine hydrogens are replaced by $\mathrm{CH}_{3}$ the formation of $\mathrm{C} \equiv \mathrm{N}$ bonds is inhibited, probably because the $\mathrm{N}-\mathrm{CH}_{3}$ bond strength is greater than that of $\mathrm{N}-\mathrm{H}$. Therefore, only the electro-oxidation of TU or MTU yields products with $\mathrm{C} \equiv \mathrm{N}$ bonds, in contrast to DMTU and TMTU, which are symmetrically $\mathrm{CH}_{3}$ di- and tetra-substituted TUs, respectively.

For TMTU electro-oxidation at $E>1.0 \mathrm{~V}$, the negative band at $1703 \mathrm{~cm}^{-1}$ suggests that the formation of carbon dioxide and sulphate ions is accompanied by some amount of $\mathrm{C}=\mathrm{O}$-containing products. Seemingly, the increase in the intensity of this band is accompanied by a decrease in the negative band at $1623 \mathrm{~cm}^{-1}$, which corresponds to disulphide formation. In this case, the formation of carbon dioxide and carbonyl-containing species is likely to be assisted by the presence of the oxygen-containing layer on platinum.

In the potential range of peak IIa, the specific electrocatalytic properties of platinum covered by $\mathrm{OH} / \mathrm{O}$ species provide the oxygen atoms necessary for the electro-oxidation of TUs and their byproducts produced in the first electro-oxidation stage. Residues remaining on the electrode surface from these reactions can be removed from the surface by electro-oxidation at higher potentials, yielding different soluble products, such as sulphate ions, carbon dioxide and nitrogen-containing species [28]. Therefore, for the second electro-oxidation stage a common main electro-oxidation reaction for TUs, in which disulphides yield carbon dioxide and sulphate ions, can be expressed as

$$
\begin{aligned}
& (\mathrm{XY}) \mathrm{N}\left(\mathrm{XY}^{\prime}\right) \mathrm{NCSSCN}(\mathrm{XY}) \mathrm{N}\left(\mathrm{XY}^{\prime}\right)+(12+2 n) \mathrm{H}_{2} \mathrm{O} \\
& \rightarrow(2+n) \mathrm{CO}_{2}+2 \mathrm{SO}_{4}^{2-}+2 \mathrm{~N}_{2}+(32+6 n) \mathrm{H}^{+} \\
& \quad+(28+6 n) \mathrm{e}^{-}
\end{aligned}
$$

where $\mathrm{X}, \mathrm{Y}$ and $\mathrm{Y}^{\prime}$ have the aforementioned meaning, and $n$ is the number of methyl groups in the disulphide molecule. According to reaction (7), the number of electrons increases from 28 for TU disulphide (FDS) to 76 for TMTU disulphide. This means that the maximal electro-oxidation charge ratio between substituted TUs and TU disulphides should be about 1.14 for MTU, 1.43 for DMTU and 2.71 for TMTU, figures however significantly larger than those derived from the anodic charges corresponding to the cyclic voltammograms (Fig. 1). This discrepancy, as expected, is consistent with a partial blockage of the electrode surface by strongly bound residues and by the formation of products of an intermediate oxidation state. The latter is consistent with the formation of cyanamide and CO-containing species, which are detected by FTIRRAS for $E>0.9 \mathrm{~V}$.

\section{Conclusions}

1. The voltammetric electro-oxidations of TU, MTU, DMTU and TMTU yielding well identified products take place in two distinct potential regions. The first one, between 0.5 and $0.9 \mathrm{~V}$, is related principally to the formation of the corresponding formamidine disulphide, whereas the second region, between 0.9 and $1.6 \mathrm{~V}$, is related to the formation of soluble products such as sulphate ions, carbon dioxide, cyanamide and CO-containing species, their relative yield depending on the type of TU considered.

2. The first electro-oxidation stage involves a competition between a reaction yielding soluble disulphides and reactions yielding adsorbed residues that interfere with the diffusion controlled electrochemical formation of disulphides.

3. The second electro-oxidation stage leading to the complete electro-oxidation of products from the first electro-oxidation stage can be described as a complex reaction also suffering interference from the presence of adsorbed residues. In this case, the electro-oxidation of TUs competes with the formation of the oxygen-containing monolayer on platinum.

4. FTIRRAS data obtained at different potentials allowed the changes in the solution constituents in the thin layer of solution to be followed. The disappearance of reactants and formation of reaction products were followed using aqueous and deuterated solutions at different applied potentials. The identification of IR bands of reactants and products at different potentials correlates with the expectations from voltammetric features.

5. Substitution in TUs plays an important role as the presence of methyl groups inhibits the formation of $\mathrm{C} \equiv \mathrm{N}$ bonds, and consequently, IR bands of cyanamide products from DMTU and TMTU are not observed.

6. The electrochemical behaviour of all TUs can be described by common reaction formalisms. Slight discrepancies resulting from TMTU can be attributed to TMTU-platinum planar adsorption interactions instead of almost linear S-platinum interactions for the other TUs.

\section{Acknowledgements}

This work was supported financially by the Consejo Nacional de Investigaciones Científicas y Técnicas (CONICET) and Agencia Nacional de Promoción Científica y Tecnológica (PICT 98 06-03251) of Argentina and the Comisión de Investigaciones Científicas de la Provincia de Buenos Aires (CIC). PLS thanks the Agencia Española de Cooperación Internacional (Spain) for the fellowship granted. 


\section{References}

[1] D. Pletcher, F. Walsh, Industrial Electrochemistry, Chapman and Hall Ltd, London, 1990.

[2] D. Gabe, Principles of Metal Surface Treatment and Protection, Pergamon Press, Oxford, 1978.

[3] K.C. Pillai, R. Narayan, J. Electrochem. Soc. 125 (1978) 1393.

[4] V.S. Martín, S. Sanllorente, S. Palmiero, Electrochim. Acta 44 (1998) 579.

[5] S. Mendez, G. Andreasen, P.L. Schilardi, M. Figueroa, L. Vázquez, R.C. Salvarezza, A.J. Arvia, Langmuir 14 (1998) 2515.

[6] D.N. Upadhayay, V. Yegnaraman, Mater. Chem. Phys. 62 (2000) 247.

[7] M. Fleischmann, I.R. Hill, G. Sundholm, J. Electroanal. Chem. 157 (1983) 359.

[8] C.A. Widrig, C. Chung, M.D. Porter, J. Electroanal. Chem. 310 (1991) 335.

[9] A.E. Bolzán, I.B. Wakenge, R.C. Salvarezza, A.J. Arvia, J. Electroanal. Chem. 475 (1999) 181.

[10] A.E. Bolzán, A.S.M.A. Haseeb, P.L. Schilardi, R.C.V. Piatti, R.C. Salvarezza, A.J. Arvia, J. Electroanal. Chem. 500 (2001) 533.

[11] S.N. Port, S.L. Horswell, R. Raval, D.J. Schiffrin, Langmuir 12 (1996) 5934.

[12] R. Holze, S. Shomaker, Electrochim. Acta 35 (1990) 613.

[13] A. Lukomska, S. Smolinski, J. Sobkowski, Electrochim. Acta 46 (2001) 3111 .

[14] D. Papapanayiotou, R.N. Nuzzo, R.C. Alkire, J. Electrochem. Soc. 145 (1998) 3366.

[15] B.G. Ateya, B.E. El-Anadouli, F.M. El-Nizamy, Corros. Sci. 24 (1984) 497.

[16] A.E. Bolzán, R.C.V. Piatti, R.C. Salvarezza, A.J. Arvia, J. Appl. Electrochem. 32 (2002) 611.

[17] R.K. Gosavi, C.N.R. Rao, J. Inorg. Nucl. Chem. 29 (1967) 1937.

[18] R.A. Bailey, T.R. Peterson, Can. J. Chem. 46 (1968) 3319.

[19] L.C. Porter, J.P. Fackler, J. Costamagna, R. Schmidt, Acta Cryst. C48 (1992) 1751.

[20] R.C. Bott, G.A. Bowmaker, C.A. Davis, G.A. Hope, B.E. Jones, Inorg. Chem. 37 (1998) 651.

[21] O.E. Piro, R.C.V. Piatti, A.E. Bolzán, R.C. Salvarezza, A.J. Arvia, Acta Cryst. B56 (2000) 993.

[22] R. Woods, in: A.J. Bard (Ed.), Electroanalytical Chemistry, vol. 9, Marcel Decker, New York, 1976, p. 98 (Chapter 1).

[23] T. Iwasita, F. Nart, in: H. Gerischer, C.W. Tobias (Eds.), Advances in Electrochemical Science and Engineering, vol. 4, VCH, Weinheim, 1995, p. 123.

[24] S.J.J. Reddy, V.N. Krishnan, J. Electroanal. Chem. 27 (1970) 473.

[25] E. Bunge, R.J. Nichols, H. Baumgärtel, H. Meyer, Ber. Bunsenges. Phys. Chem. 99 (1995) 1243.
[26] F. Scheller, R. Landsberg, H. Wolf, Electrochim. Acta 15 (1970) 525.

[27] M. Hoffmann, J.O. Edwards, Inorg. Chem. 16 (1977) 3333.

[28] M. Yan, K. Liu, Z. Jiang, J. Electroanal. Chem. 408 (1996) 225.

[29] G. Peyronel, W. Malavasi, A. Pignedoli, Spectrochim. Acta 39A (1983) 617.

[30] G. Herzberg, Molecular Spectra and Molecular Structure. II. Infrared and Raman Spectra of Polyatomic Molecules, Van Nostrand Reinhold, New York, 1945.

[31] K. Kunimatsu, M. Samant, H. Seki, M.R. Philpott, J. Electroanal. Chem. 243 (1988) 203.

[32] H. Günzler, H.-U. Gremlich, IR Spectroscopy, Wiley-VCH Verlag GmbH, Weinheim, 2002.

[33] C.J. Pouchert, The Aldrich Library of Infared Spectra, third ed., Aldrich Chemical Co, Milwakee, 1981.

[34] A. Chen, J. Richer, S.G. Roscoe, J. Lipkowski, Langmuir 13 (1997) 4737.

[35] D. Hadžic, J. Kidrič, Z.K. Kneževic, B. Barlič, Spectrochim. Acta A 32 (1976) 693.

[36] G.B. Aitken, J.L. Duncan, G.P. McQuillan, J. Chem. Soc. (A) (1971) 2695.

[37] A.E. Bolzán, T. Iwasita, A.J. Arvia, J. Electroanal. Chem. 554 555 (2003) 49.

[38] W. Wang, M.N. Schuchmann, H.-P. Schuchmann, W. Knolle, J. von Sonntag, C. von Sonntag, J. Am. Chem. Soc. 121 (1999) 238.

[39] O. Foss, J. Johnsen, O. Tvedten, Acta Chem. Scand. 12 (1958) 1782.

[40] A.E. Bolzán, T. Iwasita, A.J. Arvia, in preparation.

[41] O. Azzaroni, B. Blum, R.C. Salvarezza, A.J. Arvia, J. Phys. Chem. B 104 (2000) 1395

[42] A.E. Bolzán, R.C.V. Piatti, A.J. Arvia, J. Electroanal. Chem. 552 (2003) 19

[43] G.O. Schenck, H. Wirth, Naturwissenschaften 40 (1953) 141.

[44] W.M. Dale, J.V. Davies, Int. J. Radiat. Biol. 1 (1959) 189.

[45] R. Rivest, Can. J. Chem. 40 (1962) 2234.

[46] A. Yamaguchi, P.B. Penland, S. Mizushima, T.J. Lane, C. Curran, J.V. Qualgiano, J. Am. Chem. Soc. 80 (1958) 527.

[47] J. Stewart, J. Chem. Phys. 26 (1957) 248.

[48] Y. Mido, I. Kitagawa, M. Hashimoto, H. Matsuura, Spectrochim. Acta Part A 55 (1999) 2623.

[49] R.K. Gosavi, U. Agarwala, C.N.R. Rao, J. Am. Chem. Soc. 89 (1967) 235.

[50] K.R.G. Devi, D.N. Sathyanarayana, Bull. Chem. Soc. Japan. 53 (1980) 2990.

[51] U. Anthoni, P.H. Nielsen, G. Borch, J. Gustavsen, P. Klaboe, Spectrochim. Acta Part A 33 (1977) 403.

[52] L. Bencivenni, S.N. Cesaro, A. Pieretti, Vib. Spectrosc. 18 (1998) 91. 